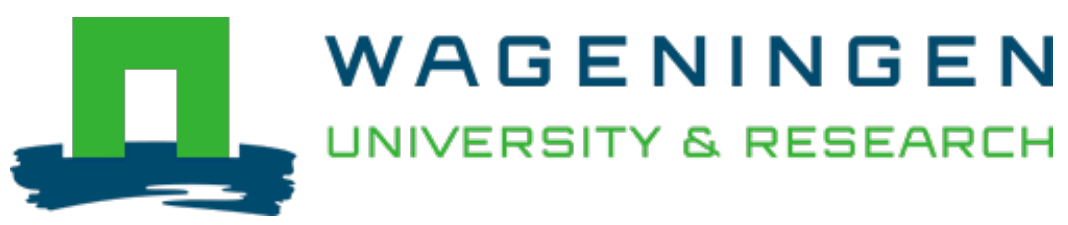

\title{
Data science at farm level : Explaining and predicting within-farm variability in potato growth and yield
}

\author{
European Journal of Agronomy \\ Mulders, Puck J.A.M.; Heuvel, Edwin R.; Borne, Jacob; Molengraft, René; Heemels, W.P.M.H. et al \\ https://doi.org/10.1016/j.eja.2020.126220
}

This article is made publicly available in the institutional repository of Wageningen University and Research, under the terms of article $25 \mathrm{fa}$ of the Dutch Copyright Act, also known as the Amendment Taverne. This has been done with explicit consent by the author.

Article 25 fa states that the author of a short scientific work funded either wholly or partially by Dutch public funds is entitled to make that work publicly available for no consideration following a reasonable period of time after the work was first published, provided that clear reference is made to the source of the first publication of the work.

This publication is distributed under The Association of Universities in the Netherlands (VSNU) 'Article $25 \mathrm{fa}$ implementation' project. In this project research outputs of researchers employed by Dutch Universities that comply with the legal requirements of Article $25 \mathrm{fa}$ of the Dutch Copyright Act are distributed online and free of cost or other barriers in institutional repositories. Research outputs are distributed six months after their first online publication in the original published version and with proper attribution to the source of the original publication.

You are permitted to download and use the publication for personal purposes. All rights remain with the author(s) and / or copyright owner(s) of this work. Any use of the publication or parts of it other than authorised under article $25 \mathrm{fa}$ of the Dutch Copyright act is prohibited. Wageningen University \& Research and the author(s) of this publication shall not be held responsible or liable for any damages resulting from your (re)use of this publication.

For questions regarding the public availability of this article please contact openscience.library@,wur.nl 


\title{
Data science at farm level: Explaining and predicting within-farm variability in potato growth and yield
}

\author{
Puck J.A.M. Mulders ${ }^{\mathrm{a}}{ }^{*}$, Edwin R. van den Heuvel ${ }^{\mathrm{b}}$, Jacob van den Borne ${ }^{\mathrm{c}}$, \\ René van de Molengraft ${ }^{\mathrm{a}}$, W.P.M.H.(Maurice) Heemels ${ }^{\mathrm{a}}$, Pytrik Reidsma ${ }^{\mathrm{d}}$ \\ ${ }^{a}$ Control Systems Technology, Department of Mechanical Engineering, Eindhoven University of Technology, P.O. Box 513, 5600 MB Eindhoven, The Netherlands \\ ${ }^{\mathrm{b}}$ Stochastics, Department of Computer Science and Mathematics, Eindhoven University of Technology, P.O. Box 513, 5600 MB Eindhoven, The Netherlands \\ ${ }^{\mathrm{c}}$ Van den Borne Aardappelen, Postelsedijk 15, 5541 NM Reusel, The Netherlands \\ ${ }^{\mathrm{d}}$ Plant Production Systems Group, Wageningen University, P.O. Box 430, 6700 AK Wageningen, The Netherlands
}

\section{A R T I C L E I N F O}

\section{Keywords:}

Yield variability

Growth modeling

Potato

The Netherlands

Mixed modeling

Within-farm

\begin{abstract}
A B S T R A C T
The growth and yield of crops within a farm largely vary among fields. Farms are increasing in size by acquiring smaller land parcels from different farmers who have different management strategies. As a result, between-field variability increases and understanding such variability is a necessity for precision farming. New data analysis techniques are needed in this context, especially given the trend that more farms are collecting more data. Therefore, this study has the objective to provide a data analysis methodology to analyze within-year variability and identify year-independent factors that influence growth. As a second objective, we applied this novel methodology to a case study, where we analyzed potato growth data of four successive years of a farm in the south of the Netherlands.

The methodology consists of three main steps: (1) describing growth using mixed models, (2) clustering and explaining growth by correlating the clusters to (a) yield, (b) other plant characteristics and (c) to defining, limiting and reducing variables, and (3) predicting growth by automatically selecting a regression model.

By applying our method on the potato growth data, we obtained the following results. The main results of the work are: (1) the estimated growth curves of the stems, haulm and tubers explain the between-field variability in growth well very well ( $R^{2}$ of $0.85,0.74$ and 0.89 , respectively), (2) clusters with a stem length between 110 and $130 \mathrm{~cm}$ have the highest average yield, (3) deeper groundwater level and sugar beet or grass as previously cultivated crop positively influence growth, and (4) $\mathrm{N}$ and $\mathrm{K}$ fertilization must be adjusted for optimal growth.

Concluding, this study responds to the quest for new data-based methods for sustainable intensification, and is the first to explicitly analyze and explain differences in crop growth between fields in practice. In addition, clear management advice could be provided, showing the scientific and practical potential of our methodology.
\end{abstract}

\section{Introduction}

The growth and yield of crops within a farm largely vary among fields. Understanding and predicting such differences are crucial for farm management. This becomes even more important with the observed increase in farm sizes (Mandryk et al., 2012), in which the number of fields increases by acquiring small land parcels that were managed by different farmers and thus have a heterogeneous past. Farm management is complicated by climate change causing extreme weather circumstances to occur more regularly (Schaap et al., 2013; Diogo et al.,
2017). Given the fact that climatic circumstances have a strong influence on the potential yield (Van Ittersum et al., 2013) and that weather circumstances at the beginning and during the season are unpredictable, it is clear that farm management is a challenging task.

To manage all fields well and enable precision farming, it is instrumental to obtain understanding of within-farm variability and the main factors that cause this. Even though weather circumstances are different between years, some soil and management variables might be preferable in all circumstances. Identifying these variables that influence withinyear variability independent of specific weather circumstances allows

\footnotetext{
* Corresponding author.

E-mail addresses: p.j.a.m.mulders@tue.nl (P.J.A.M. Mulders), e.r.v.d.heuvel@tue.nl (E.R. van den Heuvel), jacob@vandenborneaardappelen.com (J. van den Borne), m.j.g.v.d.molengraft@tue.nl (R. van de Molengraft), pytrik.reidsma@wur.nl (P. Reidsma).
} 
for a more robust management strategy at the farm to reduce withinfarm variability and increase the overall yield.

Understanding growth and variability over fields is as old as arable farming itself and over the time the methods have become more advanced. Since the 1960s, more systematic studies are conducted that aim for quantitative understanding of variability in yield (De Wit, 1959; Alberda, 1962). Many of these methods are based on experiments and/or crop growth simulation models (Affholder et al., 2013; Subedi and $\mathrm{Ma}, 2009$ ). These studies have provided valuable insights in the role of specific factors. Although these studies are important, they often focus on specific management, climatic and environmental factors, but do not lead to a complete insight and overview in how these factors all together influence yield variability. Therefore, they can only provide partial insights and partial guidance for the farmer to adjust his or her management. New agronomic research methods are necessary to accelerate innovation in identification of best management practices for a given crop, soil and climate combination, as also advocated by Cassman and Grassini (2020).

To contribute to this call, alternative methodologies can be imagined that are more empirical in nature. Such data-based methodologies are enabled by the current trend that a growing number of farms collects an increasing amount of data, which, in turn, is made possible by the availability of new data collection methods (see, e.g., the recent review (Beza et al., 2017)). Farm-collected data bring new opportunities, because they allow to investigate crop performance under farmer's conditions. This is important, because farmers' conditions differ from experimental conditions; they vary between farmers and over time. On-farm collected data can be considered equivalent to running hundreds of field experiments that capture management and interactions between management and environmental factors (Edreira-Rattalino et al., 2017). The availability of these data calls for new data analysis techniques that can explain yield variability at farm level (Cassman and Grassini, 2020; Silva et al., 2017; Delmotte et al., 2011). Such (quantitative) explanations can lead to strong advice to farmers on how, where and when to take appropriate management actions.

In practice, many potato (Solanum tuberosum L.) farms experience differences in yield (Redulla et al., 2002). One of these farms is a potato farm in the south of the Netherlands (Reidsma et al., 2015). In particular, while some fields led to more than 80 ton ha ${ }^{-1}$ yield, other fields did not obtain more than 50 ton ha ${ }^{-1}$. In addition, the farmer has intensively collected data between 2013 and 2016. Such data consist of data of the plant growth. Next to the plant growth data, the farmer collected data of the soil conditions, weather circumstances and the farm's management. This resulted in a very detailed dataset of all kinds of factors that could possibly influence variability in growth and yield.

Motivated by the above observations, the first objective of this paper is to provide a data-based methodology to model and predict withinfarm variability and identify year-independent factors influencing growth and yield. To demonstrate the validity of this novel approach, forming the second objective of this paper, we applied the new
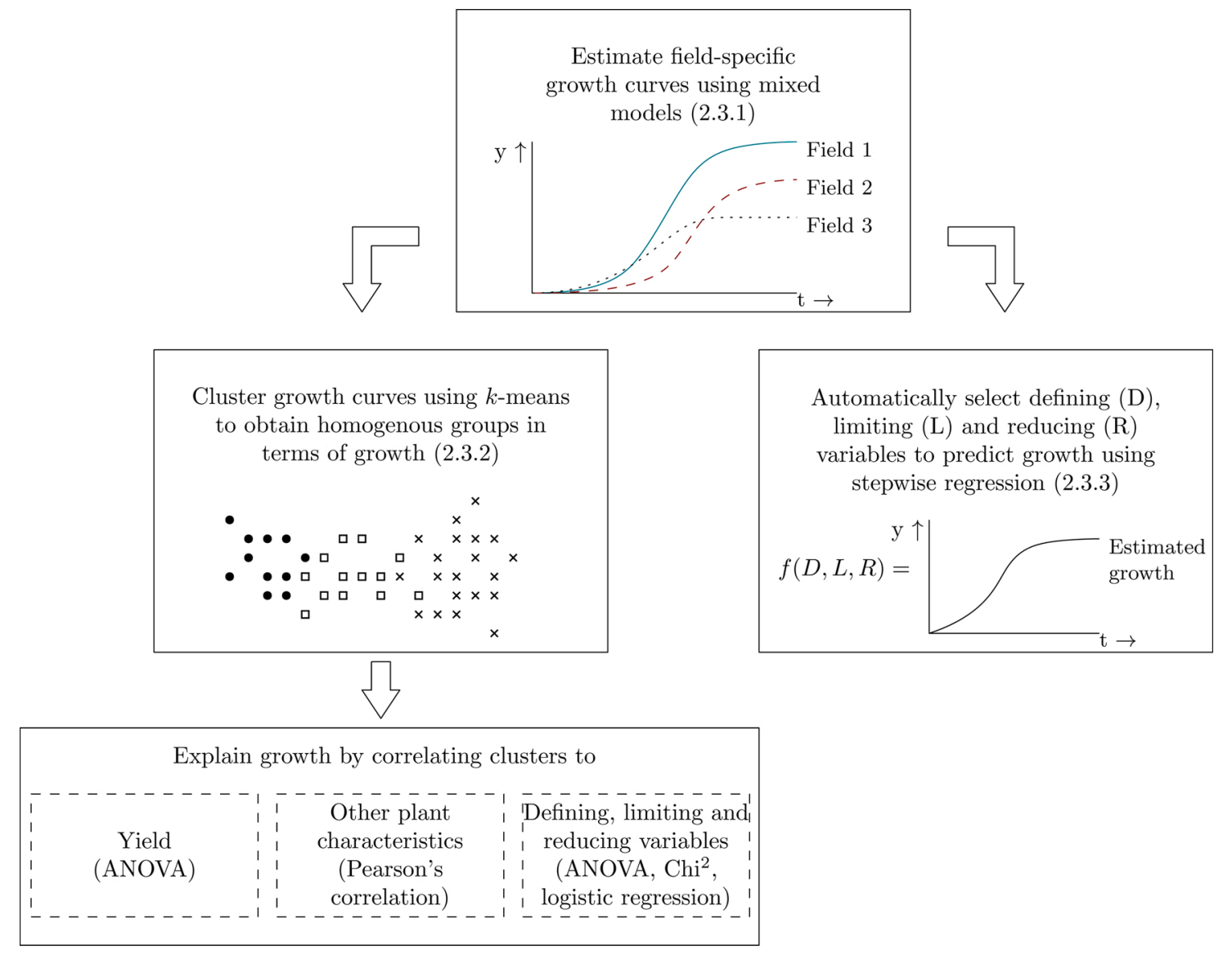

Fig. 1. Schematic representation of the proposed methodology. 
methodology on a case study of the above-mentioned potato farm in the south of the Netherlands, where we showed how the results of the methodology can result in new insights for the farmer to improve farm management.

\section{Material and methods}

\subsection{Overview of the methodology}

In the upcoming sections, we introduced our methodology to analyze between-field variability. This methodology consisted of a set of statistical methods which can be used to determine important factors that influence differences in growth. In cases where longitudinal growth data have been collected, our proposed methodology can be applied. The first step of the methodology is to describe the between-field variability using mixed models. In this step, a field-specific curve is estimated to describe the growth throughout the season. The second step is to cluster these curves by applying $k$-means to obtain homogeneous growth curves. Based on these clusters, three different relationships with growth are explained: (a) the relationship to yield, (b) to other plant characteristics, and (c) to defining, limiting and reducing variables, using techniques such as ANOVA. In the third step, covariates are automatically selected using stepwise regression for a predictive model of plant growth. By excluding year-specific effects of the mixed model, the selected covariates influence within-year variability in growth. An overview of these steps can be found in Fig. 1. In the following Sections, we start by introducing the dataset of the case study. Then, we explain each of the steps in more detail and show how to apply these steps on the data of our case study.

\subsection{Data}

The data were collected by potato farm Van den Borne Aardappelen in the Netherlands. The data from 2013 until 2016 were used. The data consisted of measurements of potato plant characteristics from around 100 fields each year (Table A.1). These fields varied from year-to-year and were located in both Belgium and the Netherlands. The farmer started collecting data with the main purpose of monitoring the potato growth on the farm's fields, so he could adjust management based on the measurements of the field. One sampling round consisted of sampling on all fields, and on each field three plants were measured. A sampling moment consisted of measuring plant characteristics, such as the stem length, haulm weight and tuber weight. All measurements have taken place at the median of the electrical conductivity of the field, as the farmer assumed that this spot represented the entire field best. Because only three plants per sampling moment were taken, it was important to verify to what extent these plants are representative for the final yield at the field (see Section 2.3.2). The samples were taken between two and seven times throughout the growing season, while 2015 and 2016 were sampled more intensively. Only fields with at least two measurements were used in this analysis.

Besides plant measurements, the data contained variables that could influence growth. These variables were divided into defining (D), limiting (L) and reducing (R) variables (Van Ittersum et al., 2003). The variables were further sub-categorized into soil (s), management (m) and weather $(w)$ variables. A detailed description of all variables can be found in Appendix A.

The farmer cultivates mainly Fontane potatoes for the French fries industry. These potatoes are grown on sandy soils. Only $22 \mathrm{~km}$ away from the farm, a meteorological station captured the temperature, radiation and rainfall. In winter (December, January and February), the measured temperature is on average $6.3^{\circ} \mathrm{C}$, while in summer (June, July and August) the mean temperature is $22.9^{\circ} \mathrm{C}(1972-2012)$. On a yearly basis, $807.1 \mathrm{~mm} \mathrm{yr}^{-1}$ precipitation falls on average. Solar radiation fluctuates between winter and summer, where it reaches its maximum of about $17.2 \mathrm{MJ} \mathrm{m}^{-2}$. The dataset was extended with field-specific sums of total amount and duration of precipitation and the temperature sum (Tsum) since planting until haulm killing. The method used to calculate the Tsum can be found in Eq. (B.1) in Appendix B. A sum of the amount and duration of solar radiation was calculated from the estimated day of emergence (30 days after planting) until haulm killing. The average relative humidity $(\mathrm{RH})$ from the day of planting until haulm killing was added to the dataset as well.

For each field, the groundwater level during summer (GLS) and winter (GLW) were added. Additionally, data about the soil type were included. The soil data from Belgium and the Netherlands were collected from soil maps (Lambert, 1990; Steur et al., 1985).

\subsection{Describing, explaining and predicting growth}

\subsubsection{Describing growth}

The first step of the methodology was to model between-field variability. We modeled variability between fields by describing the growth of the plant (characteristics) as field-specific curves. The growth was described using mixed models (Verbeke and Molenberghs, 2009). Mixed models have mixed effects. These consist of fixed effects that describe the yearly average growth, and random effects that describe the field-specific shift from this average based on the variance-covariance structure of the repeated data. Characteristics of mixed models are that they can handle missing data well and are able to model non-equidistant time intervals between measurements, allowing to model growth curves of fields with only a few observations by employing the variance-covariance structure of the entire dataset. Depending on the shape of the growth curve and the underlying distribution of the data, an appropriate mixed model was chosen (e.g., a linear, generalized linear or non-linear mixed model) (Kachman, 2000; Lindstrom and Bates, 1990). The curve of a plant characteristic was modeled according to its biological growth over time, starting at the day of planting. The quality of the fitted model was evaluated with $R^{2}$ (linear regression on observed and mixed model predicted observations). Because any inferences on the variables that cause variation between fields were based on these models, it was important that the fit of the curve was high.

For the case study of the potato farm, we estimated field-specific curves for the haulm weight, stem length and tuber weight as a function of days after planting. Each of the plant characteristics was estimated separately. The number of days after planting on which samples were taken were standardized by dividing by its standard deviation for numerical purposes only. Time was reset to zero for each year.

Haulm weight. Haulm weight has a steep increase in the beginning of the season and decreases at the end of the season due to leaf senescence (Kolbe and Stephan-Beckmann, 1997). This pattern was described with a quadratic function without intercept, i.e., the haulm weight was fit to the following linear mixed model (Eq. (1)):

$y_{\mathrm{ijk}}=\left(\beta_{k}+S_{i}\right) t_{\mathrm{ijk}}+\left(\gamma_{k}+U_{i}\right) t_{\mathrm{ijk}}^{2}+\epsilon_{\mathrm{ijk}}$

Here, $y_{\mathrm{ijk}}$ was the haulm weight in ton $\mathrm{ha}^{-1}$ on the corresponding standardized growth day $t_{\mathrm{ijk}}$ at field $i \in I=\{1, \ldots, N\}$ on day after planting $j$ at year $k \in K=\{2013,2014,2015,2016\}$ with $t_{i 1 k}=0, \forall i \in I, \forall k \in K$, 
Table 1

Fit statistics of the plant characteristics.

\begin{tabular}{lll}
\hline Plant characteristic & $R^{2}$ & Standard error \\
\hline Tuber weight & 0.887 & 6.35 \\
Stem length & 0.849 & 9.49 \\
Haulm weight & 0.736 & 5.78 \\
\hline
\end{tabular}

$\beta_{k}$ and $\gamma_{k}$ were year-specific fixed effects and $S_{i}$ and $U_{i}$ were random effects. The random effects were multivariate normally distributed according to

$$
\left(\begin{array}{c}
S_{i} \\
U_{i}
\end{array}\right) \sim \mathcal{N}\left(\left(\begin{array}{l}
0 \\
0
\end{array}\right),\left(\begin{array}{cc}
\sigma_{1}^{2} & \sigma_{12} \\
\sigma_{12} & \sigma_{2}^{2}
\end{array}\right)\right)
$$

Finally, $\epsilon_{\mathrm{ijk}}$ was the error term, which was assumed to be normally distributed $\mathcal{N}\left(0, \tau^{2}\right)$ representing variability around the growth curves. The restricted maximum likelihood was used to estimate the parameters using PROC MIXED of SAS (Singer, 1998).

Stem length. Stem length slowly increases in the beginning of the season, followed by a linear increase until the plant stops growing (Farran and Mingo-Castel, 2006; Bodlaender, 1960). This behavior was described with an S-curve. The responses of the stem length followed a normal distribution. A non-linear mixed model as in Eq. (3) was used to fit the data:

$y_{\mathrm{ijk}}=\frac{\alpha_{k}+U_{i}}{1+\exp \left(-c\left(t_{\mathrm{ijk}}-\left(\beta_{k}+S_{i}\right)\right)\right)}+\epsilon_{\mathrm{ijk}}$

Here, $y_{\mathrm{ijk}}$ was the stem length in cm on standardized day $t_{\mathrm{ijk}}$, where $j$ was the day after planting at field $i$ in year $k . \alpha_{k}$ and $\beta_{k}$ were fixed effect parameters for year $k \in K$ and $c$ was an overall fixed effect. $U_{i}$ and $S_{i}$ were random effects for field $i$. The random effects were assumed to follow a multivariate normal distribution, equivalent to the random effects of the linear mixed model in Eq. (2).

The error term $\epsilon_{\mathrm{ijk}}$ was assumed to be normally distributed, just as the error term of the haulm weight. Due to the non-linearity of the function, the marginal log likelihood was approximated with an adaptive Gauss-Hermite quadrature rule. The parameters were estimated with PROC NLMIXED with SAS (Wolfinger, 1999).

Tuber weight. The growth curve of tuber weight was S-shaped (Dyson and Watson, 1971). The same curve was used as for the stem length (Eq. (3)), where $y_{\mathrm{ijk}}$ was the tuber weight in ton ha ${ }^{-1}$ on field $i$ at day after planting $j$ in year $k$.

\subsubsection{Clustering and explaining growth}

The second step consisted of clustering field-specific growth curves to obtain homogeneous groups of fields in terms of growth. These clusters had three different purposes: (a) relate plant growth to yield, (b) relate the growth of the plant characteristics to each other, and (c) relate growth to defining, limiting and reducing variables.

The estimated $U_{i}$ and $S_{i}$ of the stem length, tuber weight and haulm weight (Eqs. (1) and (3)) were clustered separately with $k$-means (Jain, 2010), resulting in different clusters for each of the plant characteristics. $k$-means requires a pre-determined number for $k$. For $1 \leq k \leq 25$, the optimal value of $k$ was determined by calculating the BIC (Schwarz et al., 1978). We selected the number of clusters $k$, i.e., the BIC is slowing down in its improvement: the so-called elbow turning point. The elbow is often determined visually, but it is not always clear what the exact turning point is. Therefore, the BIC was determined automatically by fitting a piecewise linear change point model to the BIC points over the different number of clusters. The change point on $k$ that minimized the mean squared error was chosen as the optimal number of clusters.

Because $k$-means was applied on $U_{i}$ and $S_{i}$, the yearly-average was excluded from the clusters (which was captured in $\alpha_{k}, \beta_{k}$ and $\gamma_{k}$ of Eqs. (1) and (3)). In practice, this meant that clusters were made based on the relative shift away from the average growth, and not on the total amount of growth that a specific field experienced. This resulted in clusters consisting of fields from all years. Nominal logistic regression was used to verify if clusters contained relatively many fields from a specific year (significant if $p<0.05$ ).

For the first objective of the cluster analysis, ANOVA was applied in order to understand the influence of the growth clusters on yield. Each plant characteristic was evaluated separately, and differences between plant characteristic clusters were significant if $p<0.05$.

For the second purpose, the clusters were ranked based on the average maximum value in growth within the season, in which the clusters with rank 1 had the highest growth. As a result, each field was associated with three differently ranked clusters, corresponding to the tuber weight, stem length and haulm weight clusters. Pearson correlation was applied on these rankings of all individual fields to investigate the correlation between the different plant characteristics.

For the final purpose, one-way ANOVA for continuous variables, a Chi-square approach for binary covariates or nominal logistic regression for categorical variables were used per plant characteristic to evaluate which defining, limiting and reducing variables were significantly different among clusters, where the cluster was used as the independent variable. Each variable's relation to the plant growth cluster was evaluated separately. Differences were significant when $p<0.05$.

\subsubsection{Predicting growth}

In the third step, we automatically selected a model to predict between-field variability in growth. Here, we chose the plant characteristic that was highly correlated with yield and of which the fit of the estimated growth curves was high. In our case study, this held for the stem length (Tables 1 and 2 ). Because we were interested in the withinyear variability, our goal was to find a model that solely predicted the

Table 2

Mean yield (ton ha ${ }^{-1}$ ), standard deviation (SD) and number of fields per cluster.

\begin{tabular}{|c|c|c|c|c|c|c|c|c|c|}
\hline \multirow[t]{2}{*}{ Cluster } & \multicolumn{3}{|l|}{ Haulm weight } & \multicolumn{3}{|c|}{ Stem length } & \multicolumn{3}{|c|}{ Tuber weight } \\
\hline & Mean (ton ha ${ }^{-1}$ ) & SD & \# fields & Mean & SD & \# fields & Mean & SD & \# fields \\
\hline 1 & 68.3 & 16.1 & 15 & 66.7 & 10.9 & 20 & 62.4 & 15.2 & 24 \\
\hline 2 & 62.5 & 15.8 & 50 & 66.6 & 15.5 & 51 & 62.6 & 14.8 & 80 \\
\hline 3 & 63.5 & 14.7 & 77 & 62.5 & 14.3 & 89 & 63.4 & 15.4 & 141 \\
\hline 4 & 60.8 & 13.8 & 108 & 60.6 & 15.0 & 88 & 54.3 & 13.9 & 81 \\
\hline 5 & 56.0 & 14.5 & 72 & 56.5 & 13.6 & 79 & 49.8 & 14.8 & 36 \\
\hline 6 & 45.6 & 16.8 & 31 & 41.1 & 13.7 & 31 & - & - & \\
\hline
\end{tabular}




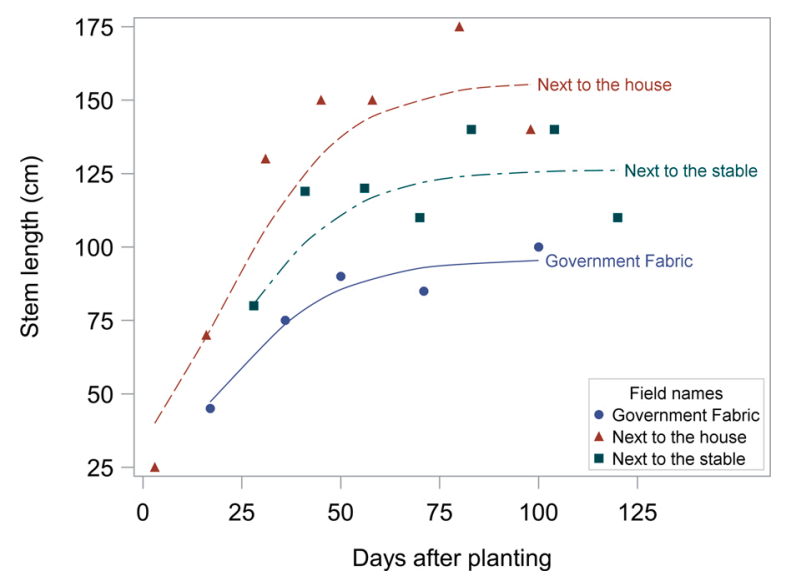

Fig. 2. Example of three fields of the actual stem length measurements and the predicted stem length.

field-specific shift from the yearly average growth curve. Therefore, we selected coefficients and their interactions that predicted random effects $U_{i}$ and $S_{i}$ of Eq. (3), and excluded $\alpha_{k}, \beta_{k}$ and $c$ from the analysis. Two separate models were created for $U_{i}$ and $S_{i}$.

For our case study, it was necessary to exclude data of the soil samples and origin of the seed samples, in contrast to the approach in Section 2.3.2. The reason was that soil data were only present for a few fields in 2015 and 2016. Using these samples would have resulted in a model that only predicts variability of a few fields within these two years, because only data with no missing values of the variables of interest could be used to create a predictive model. The origin of the seed potatoes had changed throughout the years. 2013 and 2014 had a large variety in seed potato origins and of many fields it is unknown which farm delivered the seed potatoes. Additionally, some fields were cultivated with seed potatoes from different farms, which made it impossible to trace back which origin the sampled plants had.

The correlation between all possible predictors was investigated. Predictors between which the correlation was higher than $|r|>0.7$ were considered as a possible threat for collinearity (Dormann et al., 2013). Only one predictor remained in the dataset representing the group of predictors to which that predictor was correlated, where we picked the predictor that represented the other members in the group most naturally.

After removing highly correlated predictors, stepwise regression was used to select predictors and interactions. Hierarchy was enforced: an interaction effect was only allowed when both main effects were present in the model. As a selection criterion, the AICc was used (Hurvich and Tsai, 1989). We did not consider significance of the selected model, because significance is not a reliable selection criterion and often leads to the wrong model (Ward et al., 2010; Nuzzo, 2014; Lo et al., 2015). Some categories of nominal variables consisted of only very few observations, which resulted in inflated standard errors and biasing the entire model: if such a variable was selected by AICc, these observations were removed from the dataset and stepwise regression was rerun until a stable regression model was found (e.g., no inflated standard errors anymore). The models were fit on the training set and validated on the test set using the $R^{2}$.

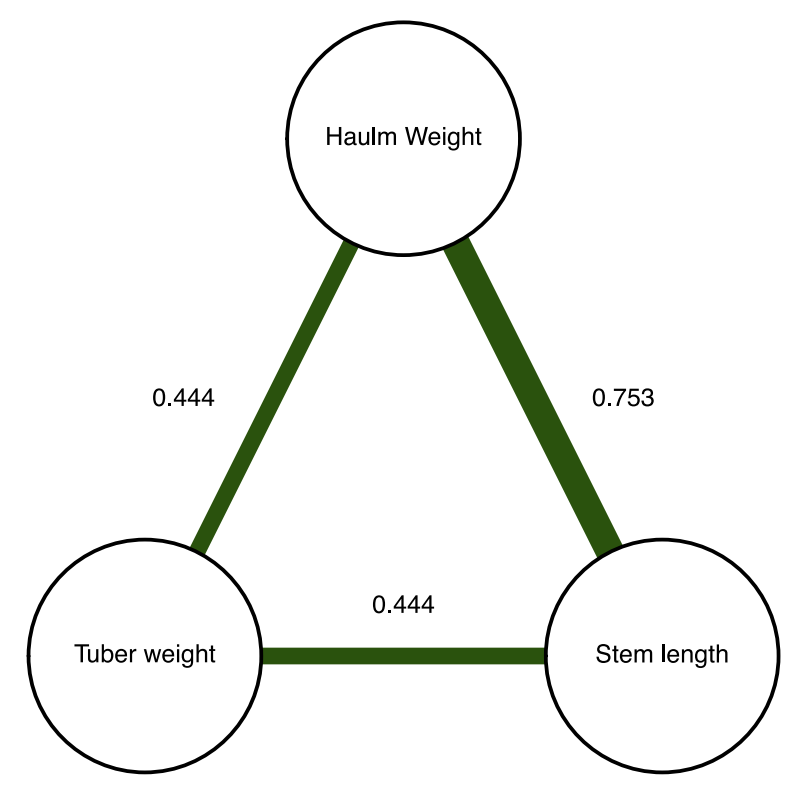

Fig. 3. Correlations between tuber growth, stem length and haulm weight.

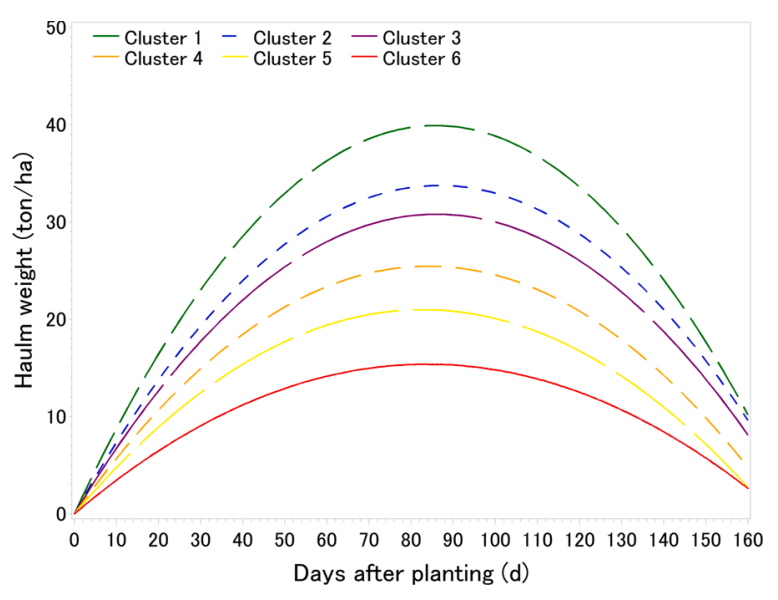

Fig. 4. Average haulm growth curve per cluster.

\section{Results}

\subsection{Describing potato growth}

In the first step, we started modeling between-field variability. The obtained $R^{2}$ of the field-specific curves of the haulm weight, tuber weight and stem length were high (Table 1 ). The high $R^{2}$ shows that the fitted models represented the variability in growth very well, despite the fact that only three plants were measured per sampling moment. This made the growth curves an appropriate basis for the analysis in step 2 and 3. As an example, Fig. 2 shows three fields with the measured and predicted stem length on different days after planting. 
Table 3

Average values of significant variables in haulm weight clusters.

\begin{tabular}{|c|c|c|c|c|c|c|c|c|c|}
\hline Cluster & $\begin{array}{l}\text { Total growing } \\
\text { days }\end{array}$ & $\begin{array}{l}\text { Planting distance } \\
(\mathrm{cm})\end{array}$ & $\begin{array}{l}\text { Days until } \\
\text { planting }\end{array}$ & $\begin{array}{l}\text { Radiation amount } \\
\left(\mathrm{MJ} \mathrm{m}^{-2}\right)\end{array}$ & $\begin{array}{l}\text { Radiation duration } \\
\text { (h) }\end{array}$ & $\begin{array}{l}\text { Tsum } \\
\left({ }^{\circ} \mathrm{C}\right)\end{array}$ & $\begin{array}{l}\text { Irrigation } \\
(\#)\end{array}$ & $\begin{array}{l}\text { GLS } \\
(\mathrm{cm})\end{array}$ & $\begin{array}{l}\mathrm{Mg} \text { in soil } \\
\left(\mathrm{kg} \mathrm{ha}^{-1}\right)\end{array}$ \\
\hline 1 & 157 & 36 & 106 & 30 & 1203 & 2507 & 0.6 & 122 & 170 \\
\hline 2 & 157 & 36 & 109 & 30 & 1220 & 2537 & 0.9 & 121 & 214 \\
\hline 3 & 152 & 33 & 110 & 30 & 1190 & 2443 & 0.8 & 116 & 270 \\
\hline 4 & 152 & 33 & 109 & 29 & 1192 & 2441 & 0.6 & 117 & 234 \\
\hline 5 & 149 & 34 & 111 & 29 & 1169 & 2409 & 0.4 & 116 & 230 \\
\hline 6 & 149 & 33 & 116 & 29 & 1166 & 2431 & 0.4 & 116 & 188 \\
\hline
\end{tabular}

Table 4

Number of significant variables per haulm weight cluster.

\begin{tabular}{lll}
\hline Cluster & No nematodes & Nematodes \\
\hline 1 & 8 & 7 \\
2 & 33 & 17 \\
3 & 55 & 22 \\
4 & 88 & 20 \\
5 & 67 & 9 \\
6 & 28 & 4 \\
\hline
\end{tabular}

\subsection{Clustering and predicting potato growth}

For the second step, we started with determining the number of clusters necessary for each plant characteristic. The change point analysis, i.e., the found elbow, showed that the field specific curves of the haulm weight and stem length should be divided into seven clusters and field specific tuber weight curves into six. One cluster of the tuber weight consisted of one field, while haulm weight and stem length both had one cluster that consisted of only two fields. These clusters consisted of fields of which the growth of that specific plant characteristic was exceptionally high. Because the interest lies in the overall trend, we decided to remove these fields for the further cluster analysis.

There was no significant relationship between the different years and clusters of the haulm weight and the tuber weight $(p>0.05)$, but the stem length showed a small significant relationship with year ( $p=$ 0.045). The last cluster contained relatively many fields of 2016 (Table C.1). This was not surprising, as this year's yield was very low (Table A.1). The other clusters consisted of more or less the same fraction of fields per year, indicating that the results showed a pattern that was relatively independent of the year-specific circumstances.

\subsubsection{Correlation between potato growth and yield}

The first purpose of clustering fields was to find the correlation between growth and yield. The average yield per cluster is provided in Table 2 . The differences in yield were significantly different between haulm weight clusters $\left(F_{(5,347)}=9.08, p<0.001, \eta^{2}=0.12,95 \%\right.$ $\mathrm{CI}=[0.05,0.17])$, stem length clusters $\left(F_{(5,351)}=55.15, p<0.001, \eta^{2}=\right.$ $0.14,95 \% \mathrm{CI}=[0.08,0.20])$ and tuber weight clusters $\left(F_{(4,352)}=9.51\right.$, $\left.p<0.001, \eta^{2}=0.10,95 \% \mathrm{CI}=[0.04,0.15]\right)$. We found a strong correlation between the growth curves and yield. This indicates that although only three plants were sampled per measure moment, the growth curves still represented the growth of the entire field fairly well. Clusters have been put in descending order with respect to the average maximum growth per cluster.

Haulm weight and stem length growth had a clear pattern in relation to yield: clusters with more haulm growth and longer stems contain often fields with more yield. In contrast to our expectation, the pattern of decreasing yield along with cluster number was less clear for the tuber weight: the first three clusters had a similar average yield, while the average yield in the last two cluster was around 10 ton ha ${ }^{-1}$ lower.

\subsubsection{Correlation between different plant characteristics}

The second purpose of the cluster analysis was to relate the growth of different plant characteristics with each other. The plant characteristics were positively correlated with each other (Fig. 3). This was expected, because stem length and haulm weight both showed a similar pattern with yield per cluster. These two plant characteristics have a slightly weaker positive correlation with tuber weight, similar to the weaker decrease in yield per cluster.

\subsubsection{Correlation between growth, soil, weather and management variables}

The final purpose of the cluster analysis was to determine the relationship between growth and defining, limiting and reducing variables. Table 5 shows an overview of variables that were significantly different among any of the plant characteristic clusters. All analyzed variables can be found in Appendix D. Each of the plant characteristics is discussed separately. The cluster with the most haulm reached on average around 40 ton $\mathrm{ha}^{-1}$ and the cluster with the least haulm growth reached only 15 ton ha $^{-1}$ (Fig. 4). The growth of the haulm weight was mainly influenced by the defining weather and management variables (Table 5). The average values and number of occurrences per haulm weight cluster were calculated to investigate if a pattern could be found in increasing growth and the significant variables (Tables 3 and 4).In line with expectations, a longer growing season and thus a larger amount and duration of radiation, a longer duration of rainfall and a larger Tsum resulted in more haulm growth. A larger planting distance between plants resulted in more haulm growth. The cluster with the most haulm growth was planted the earliest in the season and the field with the least growth was planted on average 10 days later than the first cluster. Clusters with more haulm were irrigated more often, with an exception of the first cluster. Fields in 2015 and 2016 showed an influence of $\mathrm{Mg}$ in the soil on haulm growth. Within the average haulm weight clusters, the $\mathrm{Mg}$ soil content was the highest. This indicated that $\mathrm{Mg}$ interacts with a different covariate. Fields with a deeper GLS often had more haulm growth. Unexpectedly, the clusters with more haulm growth more often suffered from nematodes (Table 4).

Six stem length clusters were identified, where the highest cluster reached a stem length of $140 \mathrm{~cm}$, while the shortest stems only reached a maximum of $60 \mathrm{~cm}$ (Fig. 5). Stem length growth was influenced by defining management and weather variables. Additionally, the limiting variables played an important role in the stem length growth (Table 5). 
Table 5

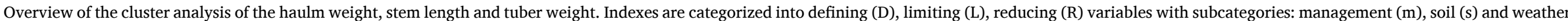

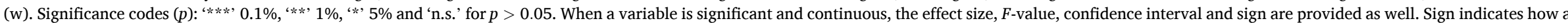

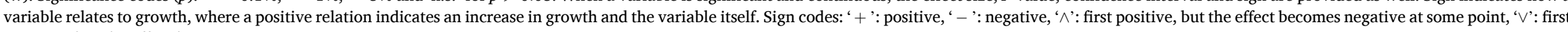
negative, but the effect becomes positive at some point.

\begin{tabular}{|c|c|c|c|c|c|c|c|c|c|c|c|c|c|c|c|c|}
\hline & & \multicolumn{5}{|l|}{ Haulm weight } & \multicolumn{5}{|l|}{ Stem length } & \multicolumn{5}{|l|}{ Tuber weight } \\
\hline & & $F$-value & $p$ & $\eta^{2}$ & $95 \% \mathrm{CI}$ & Sign & $F$-value & $p$ & $\eta^{2}$ & $95 \% \mathrm{CI}$ & Sign & $F$-value & $p$ & $\eta^{2}$ & $95 \% \mathrm{CI}$ & Sign \\
\hline \multirow[t]{5}{*}{ D.m } & Total growing days & $F_{(5,310)}=3.35$ & $* *$ & 0.051 & {$[0.0,0.09]$} & + & $F_{(5,310)}=3.91$ & $* *$ & 0.06 & {$[0.01,0.10]$} & + & & n.s. & & & \\
\hline & Planting distance & $F_{(5,352)}=2.84$ & * & 0.038 & {$[0.0,0.07]$} & + & & n.s. & & & & & n.s. & & & \\
\hline & Origin seed tubers & & n.s. & & & & & $* * *$ & & & & & n.s. & & & \\
\hline & Variety & & n.s. & & & & & $* * *$ & & & & & n.s. & & & \\
\hline & Days until planting & $F_{(5,352)}=2.52$ & * & 0.031 & {$[0.0,0.06]$} & - & $F_{(5,352)}=4.39$ & $* * *$ & 0.058 & {$[0.01,0.10]$} & $\wedge$ & & n.s. & & & \\
\hline \multirow[t]{3}{*}{ D.w } & Radiation amount & $F_{(5,310)}=2.97$ & * & 0.046 & {$[0.0,0.08]$} & + & $F_{(5,310)}=3.15$ & $* *$ & 0.048 & {$[0.0,0.09]$} & + & & n.s. & & & \\
\hline & Radiation duration & $F_{(5,310)}=2.93$ & * & 0.045 & {$[0.0,0.08]$} & + & $F_{(5,310)}=3.28$ & $*$ & 0.05 & {$[0.0,0.09]$} & + & & n.s. & & & \\
\hline & Tsum & $F_{(5,310)}=3.66$ & $* *$ & 0.056 & {$[0.01,0.10]$} & + & $F_{(5,310)}=2.74$ & * & 0.042 & {$[0.0,0.08]$} & + & & n.s. & & & \\
\hline \multirow[t]{6}{*}{ L.m } & Irrigation & $F_{(5,352)}=2.48$ & * & 0.034 & {$[0.0,0.07]$} & $\vee$ & & n.s. & & & & $F_{(4,357)}=3.33$ & * & 0.036 & {$[0.0,0.07]$} & $\mathrm{v}$ \\
\hline & $\mathrm{K}$ fertilizer (50\%) & & n.s. & & & & & n.s. & & & & $F_{(4,357)}=2.65$ & $* *$ & 0.029 & {$[0.0,0.06]$} & $\wedge$ \\
\hline & Solid $\mathrm{N}$ fertilizer & & n.s. & & & & $F_{(5,352)}=2.71$ & * & 0.037 & {$[0.0,0.07]$} & $\wedge$ & & n.s. & & & \\
\hline & $P$ from manure & & n.s. & & & & & n.s. & & & & $F_{(4,356)}=2.42$ & * & 0.026 & {$[0.0,0.06]$} & $\wedge$ \\
\hline & Liquid $\mathrm{N}$ fertilizer based on sulfite & & n.s. & & & & & n.s. & & & & $F_{(4,357)}=2.74$ & * & 0.03 & {$[0.0,0.06]$} & $\wedge$ \\
\hline & Urea & & n.s. & & & & $F_{(5,352)}=4.91$ & $* * *$ & 0.065 & {$[0.02,0.11]$} & $\vee$ & & n.s. & & & \\
\hline \multirow[t]{4}{*}{ L.s } & Clay fraction & & n.s. & & & & & n.s. & & & & $F_{(4,353)}=4.31$ & $* *$ & 0.047 & {$[0.01,0.09]$} & $\wedge$ \\
\hline & GLS & $F_{(5,345)}=2.76$ & $*$ & 0.039 & {$[0.0,0.07]$} & + & $F_{(5,345)}=2.82$ & $*$ & 0.039 & {$[0.0,0.07]$} & + & & n.s. & & & \\
\hline & $\mathrm{Mg}$ in soil & $F_{(5,122)}=3.01$ & * & 0.11 & {$[0.01,0.19]$} & $\mathrm{v}$ & & n.s. & & & & & n.s. & & & \\
\hline & $\mathrm{K}$ in soil & & n.s. & & & & $F_{(5,126)}=2.87$ & * & 0.1 & {$[0.0,0.18]$} & + & & n.s. & & & \\
\hline L.w & Rainfall duration & & n.s. & & & & $F_{(5,310)}=5.15$ & $* * *$ & 0.076 & {$[0.02,0.13]$} & + & & n.s. & & & \\
\hline R.s & Nematodes & & $* *$ & & & & & n.s. & & & & & n.s. & & & \\
\hline
\end{tabular}




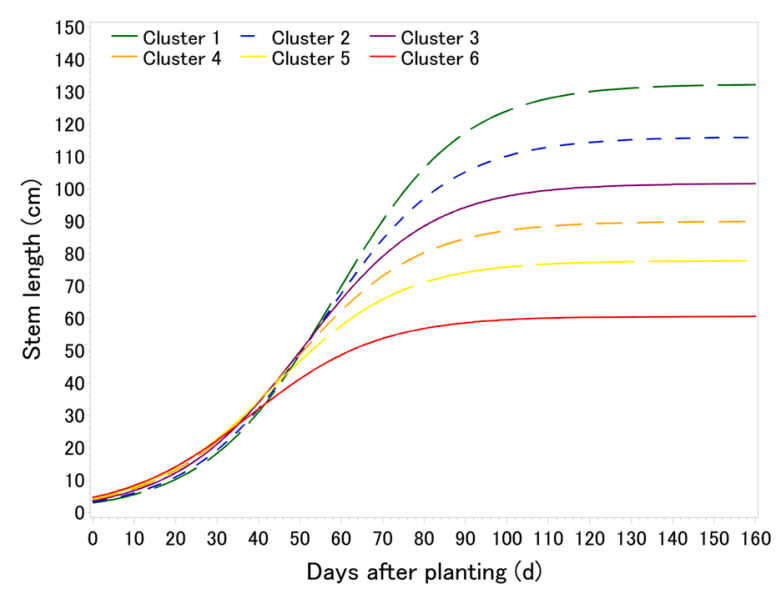

Fig. 5. Average stem length growth per cluster.

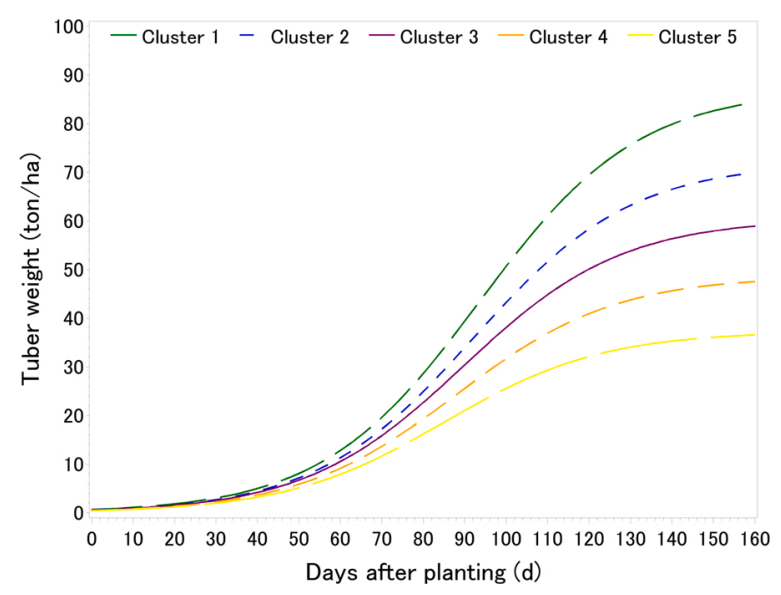

Fig. 6. Average tuber growth curve per cluster.

Per cluster, the mean of the significant variables was calculated to investigate the relationship with stem length growth and the number of occurrences per variety were given (Tables 6 and C.2). Due to the high correlation between the stem length and the haulm weight, the results of the stem length cluster analysis were similar to the haulm weight cluster analysis. A longer growing season resulted in longer stems. This directly related to the total radiation amount, radiation duration, the Tsum from planting until haulm killing and the rainfall duration. The first five clusters were planted around the same date, but the cluster with the shortest stems were planted on average a week later. A deeper GLS results in longer stems and in 2015 and 2016, a higher K soil content
Table 7

Average value per tuber weight cluster of significant variables.

\begin{tabular}{llllll}
\hline Cluster & $\begin{array}{l}\text { Irrigation } \\
(\#)\end{array}$ & $\begin{array}{l}\text { K fertilizer } \\
(50 \%) \\
\left(\mathrm{kg} \mathrm{ha}^{-1}\right)\end{array}$ & $\begin{array}{l}\text { P from } \\
\text { manure } \\
\left(\mathrm{kg} \mathrm{ha}^{-1}\right)\end{array}$ & $\begin{array}{l}\text { N fertilizer } \\
\text { based on } \\
\text { sulfite } \\
\left(1 \mathrm{ha}^{-1}\right)\end{array}$ & $\begin{array}{l}\text { Clay } \\
\text { fraction } \\
(\%)\end{array}$ \\
\hline 1 & 0.3 & 23 & 81 & 92 & 6 \\
2 & 0.9 & 3 & 89 & 79 & 5 \\
3 & 0.7 & 2 & 86 & 57 & 5 \\
4 & 0.5 & 7 & 69 & 84 & 5 \\
5 & 0.4 & 10 & 107 & 77 & 6 \\
\hline
\end{tabular}

Table 8

Fit statistics of the predictive models.

\begin{tabular}{llll}
\hline Variable & Training $R^{2}$ & Standard error & Test $R^{2}$ \\
\hline$U_{i}$ & 0.22 & 16.3 & 0.20 \\
$S_{i}$ & 0.21 & 0.17 & 0.15 \\
\hline
\end{tabular}

resulted in longer stems. High urea application was observed in clusters with medium stem growth. The clusters with shorter stems more often had fields where other varieties were cultivated than the farmer's main cultivated variety Fontane (Table C.2). There was a large variety between seed potato origin (Appendix E), of which many origins only occurred a few times within the dataset. No clear pattern could be found in these occurrences per cluster.

Five tuber weight clusters were identified and these clusters ranged between a minimum 40 ton ha ${ }^{-1}$ and a maximum of 80 ton ha $^{-1}$ at the last sampling moment (which is 2 to 4 weeks before haulm killing) (Fig. 6). In contrast to the haulm weight and stem length cluster analysis, none of the defining weather and management variables were significant (Table 5). Lack of significant defining variables related to the relatively weak relation between tuber growth during the season and final yield. Only five limiting variables were significant, of which the average values per cluster are presented in Table 7 . The clusters with a larger tuber weight had on average more water available: either the clay fraction was relatively high or it was possible to irrigate the fields. There was no clear pattern in the amount of fertilization between the tuber weight clusters. Relationships between defining, limiting and reducing variables and growth were not consistent between plant characteristics (Table 5). This suggests that we need to look at a combination of factors.

\subsection{Predicting potato growth}

In the third and final step, we created a predictive model of growth. We started detecting correlations between the predictors. Radiation amount, radiation duration, rainfall duration and Tsum were highly

Table 6

Average values of significant variables in stem length clusters.

\begin{tabular}{|c|c|c|c|c|c|c|c|c|c|c|}
\hline Cluster & $\begin{array}{l}\text { Total } \\
\text { growing days }\end{array}$ & $\begin{array}{l}\text { Days until } \\
\text { planting }\end{array}$ & $\begin{array}{l}\text { Radiation amount } \\
\left(\mathrm{MJ} \mathrm{m}^{-2}\right)\end{array}$ & $\begin{array}{l}\text { Radiation } \\
\text { duration (h) }\end{array}$ & $\begin{array}{l}\text { Tsum } \\
\left({ }^{\circ} \mathrm{C}\right)\end{array}$ & $\begin{array}{l}\text { Urea } \\
\left(1 \mathrm{ha}^{-1}\right)\end{array}$ & $\begin{array}{l}\text { GLS } \\
(\mathrm{cm})\end{array}$ & $\begin{array}{l}\text { Solid } \mathrm{N} \text { fertilizer } \\
\left(\mathrm{kg} \mathrm{ha}^{-1}\right)\end{array}$ & $\begin{array}{l}\mathrm{K} \text { in soil } \\
\left(\mathrm{kg} \mathrm{ha}^{-1}\right)\end{array}$ & $\begin{array}{l}\text { Rainfall } \\
\text { duration (h) }\end{array}$ \\
\hline 1 & 155 & 112 & 30 & 1214 & 2510 & 54 & 123 & 209 & 289 & 218 \\
\hline 2 & 156 & 111 & 30 & 1206 & 2500 & 73 & 119 & 196 & 211 & 222 \\
\hline 3 & 154 & 109 & 29 & 1197 & 2456 & 102 & 116 & 178 & 200 & 216 \\
\hline 4 & 150 & 109 & 30 & 1171 & 2419 & 115 & 118 & 177 & 177 & 206 \\
\hline 5 & 152 & 109 & 29 & 1195 & 2445 & 85 & 116 & 237 & 138 & 213 \\
\hline 6 & 143 & 119 & 29 & 1146 & 2368 & 40 & 115 & 254 & 152 & 205 \\
\hline
\end{tabular}


Table 9

Predictions of $U_{i}$. Significance codes (p): ‘***” $0.1 \%$, ‘**' $1 \%$, “*' $5 \%$ and 'n.s.' for $p>0.05$.

\begin{tabular}{|c|c|c|c|}
\hline Coefficient & Value & $p$ & Standard error \\
\hline Intercept & -22.3 & n.s. & 15.7 \\
\hline Variety: Fontane & 0 & & \\
\hline Variety: Ivory Russet & -26.9 & $* * *$ & 5.8 \\
\hline Variety: Ludmilla & -6.8 & n.s. & 6.4 \\
\hline Variety: Miranda & -12.83 & $* * *$ & 3 \\
\hline Solid $\mathrm{N}$ fertilizer $\left(\mathrm{kg} \mathrm{ha}^{-1}\right)$ & -0.019 & n.s. & 0.011 \\
\hline Urea $\left(1 \mathrm{ha}^{-1}\right)$ & -0.031 & n.s. & 0.016 \\
\hline GLS (cm) & 0.25 & n.s. & 0.13 \\
\hline Previous crop: Maize & 0 & & \\
\hline Previous crop: Grassland & -38.3 & n.s. & 32.7 \\
\hline Previous crop: Sugar beet & 93.4 & n.s. & 86.9 \\
\hline Solid N fertilizer * Maize & 0 & & \\
\hline Solid N fertilizer * Grassland & -0.027 & n.s. & 0.022 \\
\hline Solid N fertilizer * Sugarbeet & -0.0034 & n.s. & 0.038 \\
\hline Urea * Maize & 0 & & \\
\hline Urea * Grass & 0.034 & n.s. & 0.033 \\
\hline Urea * Sugar beet & 0.091 & n.s. & 0.053 \\
\hline GLS * Maize & 0 & & \\
\hline GLS * Grassland & 0.39 & n.s. & 0.27 \\
\hline GLS * Sugar beet & -0.85 & n.s. & 0.70 \\
\hline
\end{tabular}

correlated with the number of growing days. The number of growing days therefore stayed in the dataset, representing the increase in radiation, rainfall and temperature throughout the season. Some of the nutrients in the manure were correlated as well: the amount of $\mathrm{N}$ released during the season was correlated with the amount of $\mathrm{N}$ directly available. The amount of $\mathrm{N}$ released during the season was strongly correlated with the other nutrients; we chose to only keep $\mathrm{N}$ directly available in the season in the dataset. Finally, the amount of $\mathrm{Mg}$ and $\mathrm{S}$ in manure were highly correlated. $\mathrm{Mg}$ was kept, representing both the amount of $\mathrm{Mg}$ and $\mathrm{S}$ in the manure.

Stepwise regression was applied to select a predictive model for $U_{i}$ and $S_{i}$. This resulted in two regression equations, of which the coefficients are represented in Tables 9 and $10 . U_{i}$ and $S_{i}$ represent between-field variability and do not take into account the average growth per year. $U_{i}$ relates to variability in maximum stem length. Eq. (3) is a symmetric curve and $S_{i}$ relates to its midpoint, where a positive value of $S_{i}$ implies longer period until the maximum stem length is achieved.

Table 10

Predictions of $S_{i}$. Significance codes (p): ‘***' $0.1 \%$, “**' $1 \%$, '*' $5 \%$ and 'n.s.' for $p>0.05$.

\begin{tabular}{llll}
\hline Coefficient & Value & $p$ & Standard error \\
\hline Intercept & $-6.25 \times 10^{-1}$ & $* *$ & $2.25 \times 10^{-1}$ \\
P manure $\left(\mathrm{kg} \mathrm{ha}^{-1}\right)$ & $-3.38 \times 10^{-4}$ & $*$ & $1.47 \times 10^{-4}$ \\
Solid N fertilizer $\left(\mathrm{kg} \mathrm{ha}^{-1}\right)$ & $1.99 \times 10^{-3}$ & n.s. & $1.02 \times 10^{-3}$ \\
Urea $\left(\mathrm{l} \mathrm{ha}^{-1}\right)$ & $-2.60 \times 10^{-4}$ & n.s. & $1.38 \times 10^{-4}$ \\
GLS (cm) & $6.52 \times 10^{-3}$ & $* * *$ & $1.88 \times 10^{-3}$ \\
Variety: Fontane & 0 & & \\
Variety: Ivory Russet & $-2.33 \times 10^{-1}$ & $* * *$ & $5.80 \times 10^{-2}$ \\
Variety: Ludmilla & $-4.63 \times 10^{-2}$ & n.s. & $6.00 \times 10^{-2}$ \\
Variety: Miranda & $-1.44 \times 10^{-1}$ & $* * *$ & $2.98 \times 10^{-2}$ \\
GLS*Solid N fertilizer & $-2.00 \times 10^{-5}$ & $*$ & $8.66 \times 10^{-6}$ \\
\hline
\end{tabular}

The regression equations of $U_{i}$ and $S_{i}$ were fit on the training set, resulting in an $R^{2}$ of $22 \%$ for $U_{i}$ and $21 \%$ for $S_{i}$ (Table 8 ). The quality of the equations was evaluated on the test set. The regression equation of $U_{i}$ explains $20 \%$ of the variability in $U_{i}$ and the equation of $S_{i}$ explains $15 \%$ of the variability in $S_{i}$ in the test set.

Similar to the cluster analysis (Table C.2), the influence of variety on the stem length was also visible in the predictive model, where Fontane resulted in the longest stems (Table 9). The previously cultivated crop was of influence on the growth of the stems and the different interaction terms with the rotation crop suggested that preferable field conditions were different per previous crop: as maize was the reference category, a positive influence of a deeper GLS was found on these fields. The positive effect of a deep GLS was strengthened at fields previously cultivated with grass. At first glance, it seemed that the effect of a deep GLS reversed, if the previous crop was sugar beet. This effect, however, should be interpreted cautiously. In the dataset, the fields on which sugar beet was cultivated, consisted of only a small range of different GLSs, e.g., between 112 and $120 \mathrm{~cm}$, while the GLS of all fields ranged between 75 and $125 \mathrm{~cm}$. This made it hard to estimate what would happen if the GLS was shallower, for example around $80 \mathrm{~cm}$, and cultivated with sugar beet the year before. Considering main effects and interaction terms, the model predicted that long stems could be achieved on fields with sugar beet or grass as previous crop, while stems on fields previously cultivated with maize remained shorter.

Urea and the solid $\mathrm{N}$ fertilizer both had negative main coefficients: the interaction term of the solid $\mathrm{N}$ fertilizer and maize only increased the negative effect on growth. The negative effect of urea could be flipped on fields that were previously cultivated with grass or sugar beet, where a high urea application positively influenced growth.

Similar variables influencing $S_{i}$ were found (Table 10). Here, a positive coefficient corresponded to a delay in growth. Ivory Russet, Ludmilla and Miranda all mature faster than Fontane. The deeper the GLS, the larger the delay in stem growth and stem growth was delayed the most at fields that were little fertilized. High fertilization amounts increased the growth speed.

\section{Discussion}

\subsection{Explaining variability in growth: Implications for the farm}

We have applied our data analysis methodology on the case study of the Dutch potato farm. We start with shortly summarizing our main findings, and throughout the remainder of this section, we discuss how these obtained results retrieved from applying the methodology on the case study should be interpreted and can be used to improve farm management.

We started with (1) estimating field-specific curves, and results showed that these curves described between-variability in growth of the haulm weight, stem length and tuber weight very well $\left(R^{2}\right.$ of $0.74,0.85$, and 0.89 respectively). The second step, in which we clustered curves and explained growth and yield, showed that (2a) stem length and haulm weight were important for yield, while tuber weight growth had a less clear relation with yield, (2b) stem length and haulm weight were highly correlated with each other, but were less correlated with tuber growth and 2c) the most important variables that explain growth throughout the season were the length of the growing season (the longer the better), the variety, seed potato properties (origin), planting distance, GLS, the presence of nematodes, the soil content of $\mathrm{K}$ and $\mathrm{Mg}$ and finally, $\mathrm{N}$ fertilization. In the final step, (3) we automatically selected a predictive model for stem growth. In line with the results of the second step, the GLS, $\mathrm{N}$ fertilization and variety were selected to predict growth. In addition, the previously cultivated crop was selected as well.

The farmer should aim for a stem length between 110 and $130 \mathrm{~cm}$ and a haulm weight of 40 ton ha ${ }^{-1}$, because the first step showed that in clusters with that amount of growth on average 67 ton ha $^{-1}$ was 
obtained, which was 10 ton ha ${ }^{-1}$ above the average. Hence, haulm and stem growth were a good indication for final yield, as also observed in other studies (Ivins and Bremner, 1965; Khurana and McLaren, 1982; Boyd et al., 2002). To our surprise, the relation between final yield and tuber weight growth was less visible. The farmer stopped sampling between two weeks and a month before haulm killing, and apparently the tuber weight growth after this moment could be better predicted by growth of other characteristics until that moment than tuber weight itself. This may be related to the physiological age of seed tubers. Physiologically older seeds result on average in high yields in shorter growing seasons, while younger seeds perform better in longer growing seasons (Caldiz et al., 2001). Older seeds might have already reached maturity at last sampling point, while the younger seeds continued growing in that final period, closing the gap in weight with the older seeds. Also, abundant water and nutrient availability may lead to more stem and haulm growth as compared with tuber growth early in the season, but providing resources for additional tuber growth at the end of the season.

In the second step, we identified other important seed potato properties (next to physiological age). Firstly, the origin of the different seed potatoes (which is likely related to physiological age) influenced stem growth. A second important variable related to seed properties was the planting distance, where a larger planting distance correlated to more haulm per hectare. At this specific farm, large seed potatoes are planted with more space between them and large seed potatoes are often planted earlier, because the farmer believes that this is more beneficial for the final yield. Although the differences in growth depending on planting distance and origin indicated that seed potato quality correlated to between-field variability, these variables were highly linked to the vision of the farmer and it is unclear what would happen if the farmer changes this strategy. As our research confirms that seed potato quality is an important factor determining final yield (Struik and Wiersema, 1999), more research is needed to investigate the exact influence of seed potato quality on yield.

Plants with a high tuber weight, long stems and a high haulm weight were expected on irrigated fields with a deep GLS: these fields did not only experience less stress of an excess of water, they experienced less stress of a lack as water as well. A likely explanation of this effect is that a shallower GLS increased stress of water excess, which reduced stem length and haulm growth (Van Loon, 1981; Deblonde and Ledent, 2001). The tuber weight cluster analysis results indicated that the fields within the lowest cluster experienced stress of water excess as well: the clay fraction was on average high and therefore these fields had a higher water holding capacity (Dunne and Willmott, 1996). These results are similar to results of Maestrini and Basso (2018), who showed that across the USA, yields are more unstable in very wet fields. Finally, we observed that fields with more haulm more often had nematodes. This related to the GLS: nematodes disease incidence was higher on dry soil conditions (e.g., having a deep GLS) than on wet soil conditions (with a shallow GLS) (Lootsma and Scholte, 1997). This indicated that preventing a lack of excess of water was more important than the presence of nematodes, and that still high yields could be obtained on fields with nematodes.

Soil data were only available in 2015 and 2016, and two soil nutrients were identified as significant in the cluster analysis, implying that at least in these two years a similar effect of nutrients was found. At this farm, there could be an opportunity to improve $\mathrm{K}$ application, as we found that the longer the stems, the higher the K soil content, but we did not observe that clusters with a low $\mathrm{K}$ soil content had a higher potassium application through fertilizer or manure. In addition, the $\mathrm{Mg}$ soil content in the average haulm weight clusters was high and was slightly lower within the clusters with the most and smallest haulm growth. This pattern implied that $\mathrm{Mg}$ interacted with another variable. As interactions were not considered in the cluster analysis, we cannot determine with exact certainty with which variable $\mathrm{Mg}$ interacted. However, haulm weight and stem length clusters were highly correlated and it is thus likely that the data patterns between clusters for these plant characteristics were similar (although not necessarily significant). As we know that a high Mg soil content limits K availability (Laughlin, 1966; Laekemariam et al., 2018), it might be that the decrease in stem length and haulm weight was strengthened due to the high $\mathrm{Mg}$ amount in the average growth clusters.

Besides $\mathrm{K}$ application, $\mathrm{N}$ application is of relevance. The effect of solid $\mathrm{N}$ fertilizer and urea, however, were not consistent between the cluster analysis and the predictive model. For example, solid $\mathrm{N}$ fertilizer always had a negative effect in the predictive model, while the fields within the clusters with the longest stems had the largest amount of solid $\mathrm{N}$ fertilizer applied on them. A possible reason why it may be hard to estimate the exact effect of $\mathrm{N}$ fertilization on stem length is that the response to fertilization depends on secondary nutrients, micronutrients and soil carbon (Kihara et al., 2016), and it is unknown how these conditions differed from field-to-field. The interaction terms between urea or the solid $\mathrm{N}$ fertilizer and the previous crop support this: each rotation crop has a different influence on the nutrient content and organic matter in the soil (Riedell et al., 2009; Lemaire et al., 2015; Götze et al., 2016), influencing the response to fertilization. Another reason is that fertilizer $\mathrm{N}$ application is relatively high and similar across field, similar to the rest of the Netherlands (Silva et al., 2017). Under such conditions, also other studies found little yield response to $\mathrm{N}$ application (Silva et al., 2017). Additional research is required to investigate which soil properties influence response to $\mathrm{N}$ fertilization.

At this specific farm, many of the fields are rented and the area in which the fields lie, is large. As a result, it takes around 45 days to plant all fields. Because the farmer does not control what happens to the soil in the years that he is not cultivating it, strategically planning when to plant which field with what type of seed potato highly influences plant growth and final yield. When renting a field, GLS, the soil K content and the previous cultivated crop can help to indicate how much growth is expected. On these fields, the farmer could plant early in the season to enforce a long growing season to improve stem and haulm growth resulting in high yields. Furthermore, results suggest that larger and physiologically younger seed potatoes result in longer growth and higher yields, but this should be further investigated experimentally.

\subsection{Implications for other farms}

As farms are increasing in size (Mandryk et al., 2012), more farms are challenged with a longer planting period and a more heterogeneous soil. All large farms require a planting strategy, facing the same decisions as this specific farm. In addition, we expect that in a moderate maritime climate, similar results should be found on sandy soils. Because of the limited water holding capacity of sandy soils, it is likely that the combination of irrigation and a low GLS avoids both a lack and an excess of water.

If farms would like to monitor their own within-farm variability in growth, the first question to be answered is on what spatial scale variability is observed. The farm of the case study cultivates many small fields, many having an area of only 2 ha, and it thus makes sense to 
sample per field. Other farms may consist of only a few very large fields. In such cases, it could be beneficial to determine zones, for example, based on electrical conductivity of the soil (Corwin and Lesch, 2005). When choosing which fields or zones to follow, the farmer should ensure that these fields are randomly sampled, e.g., ensuring that both good and bad fields are sampled and that they are randomly distributed over the total areal. In order to estimate field-specific growth curves, it is necessary to determine an appropriate sample size and a number of repeated measures per zone or field. This is, however, a trade-off between the considered fields or zones and the number of repeated measures per field or zone, where the absolute minimum of repeated measures is three (Curran et al., 2010). Non-linear growth curves require slightly more data points per field or zone, because they describe three different stages during growth (Grimm et al., 2011).

Destructive sampling of different plant characteristics throughout the season enables to model growth throughout the season. At the case study, only three plants were sampled at each sampling moment. Nevertheless, the plant growth clusters showed a strong correlation with yield. A possible explanation for the strong correlation between growth and yield is that the total sampled area spanned around $5 \mathrm{~m}^{2}$, because at most fields 6 or 7 repeated measurements were performed. However, there were still inconsistencies in the relationship between yield and growth. This indicates that further research is necessary to investigate what sampling strategy is necessary to get a good representation of an entire field.

\subsection{Methodological considerations}

The proposed methodology is applicable to analyze data on farmlevel, but it can also be applied to data of multiple farms. When on a farm or farms longitudinal data have been collected, mixed models provide an efficient way to model the between-field variability. This methodology handles missing data well and is robust against samples with non-equidistant spacing (Curran et al., 2010). Additionally, mixed models allow the modeler to choose an appropriate function to describe growth.

Our methodology consists of three steps, where step 2 and 3 are used to investigate between-field differences. Clustering fields allows for an initial screening of all variables to determine which factors play an important role in defining, limiting and reducing growth. Furthermore, it gives clear insight in the relationship between the growth development and yield. The second analysis selects a predictive model that allows to investigate more complex relationships between factors and growth. Because a linear regression model is used to predict growth, the relation between growth and the factors is easy to interpret. Explanatory power of the models was still relatively small, but this is common when analyzing farm data, because of multiple factors that interact (Silva et al., 2020; van Heerwaarden et al., 2018).

In the third step, we selected some non-significant variables, because we used the AICc as the selection criterion. Non-significant variables remained in the model. Significance is not a good indicator for predictive power. Moreover, selecting on basis of significance, often leads to the wrong model (Ward et al., 2010; Nuzzo, 2014; Lo et al., 2015). As we were searching for a model with high predictive model, we did not rely on significance to validate the quality of the model, but on predictive power on unseen data (e.g., the test set).

The plants were sampled at the median of the electrical conductivity of the field, while the defining, limiting and reducing variables are often related to average values of the field or to the weather conditions of the complete area. Because data are collected by a farmer and data collection is costly in both time and money, collecting more data of the plant on multiple spots within the field is often not possible in practice. However, the current data collection already allows to model variability between fields and gives opportunities to farmers to collect this type of data themselves.

In this paper, data from 2013 until 2016 were analyzed. Within-year variability was analyzed that were independent of year-specific conditions. Effects that are only present in specific weather circumstances are not found due to the focus of the study. However, the methodology can be applied to investigate year-specific differences as well.

\section{Conclusion}

Applying the methodology on the case study of a potato farm in the south of the Netherlands led to the following results. Stem length and haulm weight appeared to be indicators for the potential final potato yield, where good yields were obtained if the stems were between 110 and $130 \mathrm{~cm}$ long and the haulm weighs around 40 ton ha $^{-1}$ (yields are on average 67 ton ha ${ }^{-1}$ in these clusters). Because more haulm was associated with more yield, management could be improved by monitoring and controlling the haulm growth throughout the season. The relation between tuber growth and yield was less visible. This indicates that the potato growth at the end of the season was important for the final yield. Sampling potatoes in this period could help to improve understanding of the relationship between tuber growth and yield.

Variability in growth could mainly be explained by the length of the growing season (i.e., planting date) and other defining variables such as the planting distance and the variety. Further, fields previously cultivated with grass or sugar beet, and fields with a deep groundwater level during summer, especially if they are irrigated, had higher stem growth, resulting in higher yields. The latter indicated that preventing stress from both an excess and a lack of water was important. By anticipating where and how higher growth and yields can be expected, the farmer can tactically decide when to plant what.

Further, application of inputs should be adapted to expected growth and yield. The farmer should reduce the amount of $\mathrm{N}$ application on these fields, applying just enough nutrients for the total growth, as our analysis showed that fields with very short stems and low yields were often fertilized intensively. In addition, the farmer should consider variable $\mathrm{K}$ fertilization to compensate for differences in $\mathrm{K}$ availability: more growth was found on fields with a higher amount of $\mathrm{K}$ in the soil, while no effect of $\mathrm{K}$ fertilizer was found on growth, which indicates that fields with more growth thus had on average more $\mathrm{K}$ to their disposal.

This article mainly focused on identifying factors that are independent of weather circumstances influencing potato yield. Future work should investigate how year-specific conditions influence between-field variability. Years with beneficial weather circumstances could require a different management protocol than years with large periods of drought or extensive rain. Additionally, the influence of within-season management decisions should be investigated to optimize operational management.

\section{Authors' contribution}

Puck Mulders: software, methodology, conceptualization, formal analysis, writing - original draft, visualization; Edwin van den Heuvel: methodology, validation, conceptualization, writing - review and editing, supervision; Jacob van den Borne: resources, investigation, data curation; René van de Molengraft and Maurice Heemels: conceptualization, writing - review and editing, supervision, project administration, funding acquisition; Pytrik Reidsma: conceptualization, formal analysis, writing - review and edition, supervision.

\section{Declaration of Competing Interest}

The authors report no declarations of interest.

\section{Acknowledgements}

We thank Rick Rasenberg, who worked on this project. This work is part of the OPZuid project "Proeftuin voor Precisielandbouw", funded 
by the European Regional Development Fund, the Dutch Ministry of Economic Affairs and the province of Noord-Brabant.

\section{Appendix A}

Table A.1

Number of fields and final yield per year.

\begin{tabular}{llll}
\hline Year & Number of fields & Yield $\left(\right.$ ton $\left.\mathrm{ha}^{-1}\right)$ & Standard deviation \\
\hline 2013 & 112 & 60 & 13 \\
2014 & 135 & 69 & 13 \\
2015 & 133 & 62 & 14 \\
2016 & 112 & 44 & 13 \\
\hline
\end{tabular}

Table A. 2

Description of data, categorized into defining (D), limiting (L) and reducing (R) factors with subcategories management (m), soil (s) and weather (w).

\begin{tabular}{|c|c|c|c|c|c|c|}
\hline Variable & Index & Unit & Scale & Time & Source & Additional comments \\
\hline Haulm weight & & ton ha $\mathrm{h}^{-1}$ & Field & $2-7$ times per season & Farmer & $\begin{array}{l}\text { Three plants are pulled and weighed in grams, transformed } \\
\text { to kilos per hectare (Appendix B, Eq. (B.2)) }\end{array}$ \\
\hline Stem length & & $\mathrm{cm}$ & Field & $2-7$ times per season & Farmer & Average length of three plants \\
\hline Tuber weight & & ton ha $\mathrm{h}^{-1}$ & Field & $2-7$ times per season & Farmer & $\begin{array}{l}\text { Three plants are pulled out and weighed in grams, } \\
\text { transformed to kilos per hectare (Appendix B, Eq. (B.2)) }\end{array}$ \\
\hline Yield & & ton ha $\mathrm{h}^{-1}$ & Field & End & Weighed on the bridge & \\
\hline Variety & D.m & Name & Field & Start & Seed grower & $\begin{array}{l}\text { Fontane, Ivory Russet, Ludmilla, Miranda, Dakota, Lady } \\
\text { Anna }\end{array}$ \\
\hline Seed tuber origin & & Name & Field & Start & Seed grower & Varies, see Appendix ref \\
\hline Planting distance & & $\mathrm{cm}$ & Field & Start & $\begin{array}{l}\text { Setting planting } \\
\text { machine }\end{array}$ & $\begin{array}{l}\text { Planting distance is decided by the farmer based on the size } \\
\text { of the seed potatoes and the expected fertility of the field }\end{array}$ \\
\hline Growing days planting & & Days & Field & Start & $\begin{array}{l}\text { Start counting from } \\
\text { planting }\end{array}$ & Summations stops at haulm killing \\
\hline Radiation amount & D.w & $\mathrm{J} \mathrm{cm}^{-2}$ & Region & $\begin{array}{l}\text { Daily from estimated } \\
\text { day of emergence }\end{array}$ & $\begin{array}{l}\text { Weather station KNMI } \\
\text { in Eindhoven }\end{array}$ & Summation stops at haulm killing \\
\hline Radiation duration & & Hour & Region & $\begin{array}{l}\text { Daily from estimated } \\
\text { day of emergence }\end{array}$ & $\begin{array}{l}\text { Weather station KNMI } \\
\text { in Eindhoven }\end{array}$ & Summation stops at haulm killing \\
\hline Temperature sum (Tsum) & & ${ }^{\circ} \mathrm{C}$ day $^{-1}$ & Region & $\begin{array}{l}\text { Daily from planting } \\
\text { until haulm killing }\end{array}$ & $\begin{array}{l}\text { Weather station KNMI } \\
\text { in Eindhoven }\end{array}$ & $\begin{array}{l}\text { Summation stops when haulm is killed. See Appendix B for } \\
\text { the specific calculation of the Tsum (Eq. (B.1)) }\end{array}$ \\
\hline Irrigation & L.m & $\#$ & Field & During growing season & $\begin{array}{l}\text { Van den Borne } \\
\text { Aardappelen }\end{array}$ & \\
\hline K fertilizer (50\%) (K50) & & $\mathrm{kg} \mathrm{ha}^{-1}$ & Field & During growing season & $\begin{array}{l}\text { Van den Borne } \\
\text { Aardappelen }\end{array}$ & $\mathrm{K}$ fertilizer containing $50 \% \mathrm{~K}$, only applied in 2013 \\
\hline K fertilizer $(60 \%)(\mathrm{K} 60)$ & & $\mathrm{kg} \mathrm{ha}^{-1}$ & Field & During growing season & $\begin{array}{l}\text { Van den Borne } \\
\text { Aardappelen }\end{array}$ & $\mathrm{K}$ fertilizer containing $60 \% \mathrm{~K}$, applied in $2014-2016$ \\
\hline Solid N fertilizer (KAS) & & $\mathrm{kg} \mathrm{ha}^{-1}$ & Field & During growing season & $\begin{array}{l}\text { Van den Borne } \\
\text { Aardappelen }\end{array}$ & $\mathrm{N}$ fertilizer \\
\hline Manure type & & Name & Field & During growing season & $\begin{array}{l}\text { Van den Borne } \\
\text { Aardappelen }\end{array}$ & $\begin{array}{l}\text { Meat cow manure, calf manure, dairy manure, pig manure, } \\
\text { goat manure, chicken manure, compost }\end{array}$ \\
\hline Manure amount & & $\mathrm{m}^{3} \mathrm{ha}^{-1}$ & Field & During growing season & $\begin{array}{l}\text { Van den Borne } \\
\text { Aardappelen }\end{array}$ & \\
\hline Magnesium from manure & & $\mathrm{kg} \mathrm{ha}^{-1}$ & Field & Start & $\begin{array}{l}\text { Van den Borne } \\
\text { Aardappelen }\end{array}$ & Estimated amount based on manure type \\
\hline Nitrogen from manure & & $\mathrm{kg} \mathrm{ha}^{-1}$ & Field & Start & $\begin{array}{l}\text { Van den Borne } \\
\text { Aardappelen }\end{array}$ & Estimated amount based on manure type \\
\hline $\begin{array}{l}\text { Nitrogen released during } \\
\text { season from manure }\end{array}$ & & $\mathrm{kg} \mathrm{ha}^{-1}$ & Field & Start & $\begin{array}{l}\text { Van den Borne } \\
\text { Aardappelen }\end{array}$ & Estimated amount based on manure type \\
\hline Phosphorus from manure & & $\mathrm{kg} \mathrm{ha}^{-1}$ & Field & Start & $\begin{array}{l}\text { Van den Borne } \\
\text { Aardappelen }\end{array}$ & Estimated amount based on manure type \\
\hline Potassium from manure & & $\mathrm{kg} \mathrm{ha}^{-1}$ & Field & Start & $\begin{array}{l}\text { Van den Borne } \\
\text { Aardappelen }\end{array}$ & Estimated amount based on manure type \\
\hline Sulfite from manure & & $\mathrm{kg} \mathrm{ha}^{-1}$ & Field & Start & $\begin{array}{l}\text { Van den Borne } \\
\text { Aardappelen }\end{array}$ & Estimated amount based on manure type \\
\hline $\mathrm{N}$ fertilizer based on sulfite & & $1 \mathrm{ha}^{-1}$ & Field & During growing season & $\begin{array}{l}\text { Van den Borne } \\
\text { Aardappelen }\end{array}$ & Liquid nitrogen fertilizer (sulfazote) \\
\hline Urea & & lha $\mathrm{h}^{-1}$ & Field & During growing season & $\begin{array}{l}\text { Van den Borne } \\
\text { Aardappelen }\end{array}$ & Liquid nitrogen fertilizer \\
\hline \multirow[t]{2}{*}{$\begin{array}{l}\text { Groundwater level during } \\
\text { summer (GLS) }\end{array}$} & L.s & $\mathrm{cm}$ & Field & Start & Soil maps & \\
\hline & & $\mathrm{cm}$ & Field & Start & Soil maps & \\
\hline
\end{tabular}


Table A.2 (continued)

\begin{tabular}{|c|c|c|c|c|c|c|}
\hline Variable & Index & Unit & Scale & Time & Source & Additional comments \\
\hline \multicolumn{7}{|l|}{$\begin{array}{l}\text { Groundwater level during } \\
\text { winter }\end{array}$} \\
\hline Boron soil sample & & $\mathrm{gha}^{-1}$ & Field & $\begin{array}{l}\text { After applying organic } \\
\text { manure }\end{array}$ & Eurofins protocol & $\begin{array}{l}\text { Collected since } 2015 \text {, measured at the same place as the spot } \\
\text { on which the samples are taken }\end{array}$ \\
\hline Calcium soil sample & & $\mathrm{kg} \mathrm{ha}^{-1}$ & Field & $\begin{array}{l}\text { After applying organic } \\
\text { manure }\end{array}$ & Eurofins protocol & $\begin{array}{l}\text { Collected since } 2015 \text {, measured at the same place as the spot } \\
\text { on which the samples are taken }\end{array}$ \\
\hline Iron soil sample & & $\mathrm{gha}^{-1}$ & Field & $\begin{array}{l}\text { After applying organic } \\
\text { manure }\end{array}$ & Eurofins protocol & $\begin{array}{l}\text { Collected since } 2015 \text {, measured at the same place as the spot } \\
\text { on which the samples are taken }\end{array}$ \\
\hline Magnesium soil sample & & $\mathrm{kg} \mathrm{ha}^{-1}$ & Field & $\begin{array}{l}\text { After applying organic } \\
\text { manure }\end{array}$ & Eurofins protocol & $\begin{array}{l}\text { Collected since } 2015 \text {, measured at the same place as the spot } \\
\text { on which the samples are taken }\end{array}$ \\
\hline Manganese soil sample & & $\mathrm{g} \mathrm{ha}^{-1}$ & Field & $\begin{array}{l}\text { After applying organic } \\
\text { manure }\end{array}$ & Eurofins protocol & $\begin{array}{l}\text { Collected since } 2015 \text {, measured at the same place as the spot } \\
\text { on which the samples are taken }\end{array}$ \\
\hline Nitrogen soil sample & & $\mathrm{kg} \mathrm{ha}^{-1}$ & Field & $\begin{array}{l}\text { After applying organic } \\
\text { manure }\end{array}$ & Eurofins protocol & $\begin{array}{l}\text { Collected since } 2015 \text {, measured at the same place as the spot } \\
\text { on which the samples are taken }\end{array}$ \\
\hline Phosphorus soil sample & & $\mathrm{kg} \mathrm{ha}^{-1}$ & Field & $\begin{array}{l}\text { After applying organic } \\
\text { manure }\end{array}$ & Eurofins protocol & $\begin{array}{l}\text { Collected since } 2015 \text {, measured at the same place as the spot } \\
\text { on which the samples are taken }\end{array}$ \\
\hline Zinc soil sample & & $\mathrm{gha}^{-1}$ & Field & $\begin{array}{l}\text { After applying organic } \\
\text { manure }\end{array}$ & Eurofins protocol & $\begin{array}{l}\text { Collected since } 2015 \text {, measured at the same place as the spot } \\
\text { on which the samples are taken }\end{array}$ \\
\hline Nutrient content & & Class & Field & Beginning of the season & Eurofins protocol & Estimated by the farmer \\
\hline Rainfall amount & L.w & $\mathrm{mm}$ & Region & Daily from planting & $\begin{array}{l}\text { Weather station KNMI } \\
\text { in Eindhoven }\end{array}$ & Summation stops at haulm killing \\
\hline Rainfall duration & & Hour & Region & Daily from planting & $\begin{array}{l}\text { Weather station KNMI } \\
\text { in Eindhoven }\end{array}$ & Summation stops at haulm killing \\
\hline Relative humidity & & $\%$ & Region & Daily from planting & $\begin{array}{l}\text { Weather station KNMI } \\
\text { in Eindhoven }\end{array}$ & Summation stops at haulm killing \\
\hline Granule & R.m & Yes or no & Field & Start & $\begin{array}{l}\text { Van den Borne } \\
\text { Aardappelen }\end{array}$ & Applied to control nematodes \\
\hline Previous crop & & Name & Field & Start & $\begin{array}{l}\text { Van den Borne } \\
\text { Aardappelen }\end{array}$ & Cultivated by Van den Borne or a different farmer \\
\hline Nematodes & R.s & Yes or no & Field & Start & $\begin{array}{l}\text { Van den Borne } \\
\text { Aardappelen }\end{array}$ & Pest affecting potatoes \\
\hline
\end{tabular}

\section{Appendix B}

$\operatorname{Tsum}_{1}=\sum_{i}\left\{\begin{array}{cl}\frac{\max \left(t_{i}\right)+\min \left(t_{i}\right)}{2} & \text { if } 2 \leq \frac{\max \left(t_{i}\right)+\min \left(t_{i}\right)}{2} \leq 30 \\ 0 & \text { otherwise }\end{array}\right.$ where $i$ is growing day

$y\left(\right.$ ton $\left.\mathrm{ha}^{-1}\right)=\frac{\tilde{y}(\mathrm{~g} / 3 \text { plants }) * 13.333 * 0.85)}{\text { planting distance }(\mathrm{cm}) * 3 / 100)}$

Where we correct for the row distance of $75 \mathrm{~cm}$ and for a yield loss of 15\% (e.g., 85\% yield remains).

\section{Appendix C}

Table C.1

Number of fields per year in the stem length clusters.

\begin{tabular}{lllll}
\hline Cluster & 2013 & 2014 & 2015 & 2016 \\
\hline 1 & 5 & 4 & 5 & 6 \\
2 & 18 & 9 & 12 & 12 \\
3 & 29 & 28 & 17 & 15 \\
4 & 29 & 32 & 10 & 17 \\
5 & 22 & 19 & 20 & 18 \\
6 & 7 & 2 & 7 & 15 \\
\hline
\end{tabular}

Table C.2

Counts per stem length cluster of variety. Stems are the longest in cluster 1 .

\begin{tabular}{lllllll}
\hline & Fontane & Ivory Russet & Ludmilla & Miranda & Dakota & Lady Anna \\
\hline 1 & 20 & 0 & 0 & 0 & 0 & 0 \\
2 & 50 & 0 & 0 & 1 & 0 & 0 \\
3 & 74 & 1 & 5 & 9 & 0 & 0 \\
4 & 71 & 1 & 4 & 12 & 0 & 0 \\
5 & 59 & 1 & 2 & 14 & 2 & 1 \\
6 & 13 & 9 & 0 & 9 & 0 & 0 \\
\hline
\end{tabular}




\section{Appendix D}

\section{Table D.1}

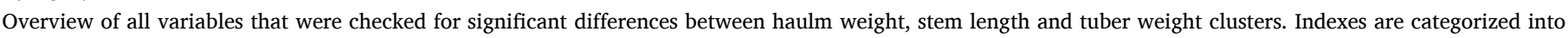

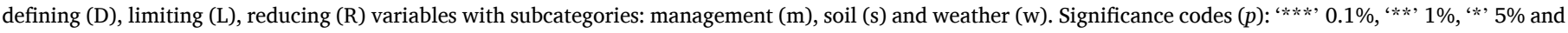
'n.s.' for $p>0.05$.

\begin{tabular}{|c|c|c|c|c|}
\hline & & Haulm weight & Stem length & Tuber weight \\
\hline \multirow[t]{6}{*}{ D.m } & Total growing days & $* *$ & $* *$ & n.s. \\
\hline & Planting distance & * & n.s. & n.s. \\
\hline & Size of the seed tubers & n.s. & n.s. & n.s. \\
\hline & Origin seed tubers & n.s. & $* * *$ & n.s. \\
\hline & Variety & n.s. & $* * *$ & n.s. \\
\hline & Days until planting & * & $* * *$ & n.s. \\
\hline \multirow[t]{3}{*}{ D.w } & Radiation amount & * & $* *$ & n.s. \\
\hline & Radiation duration & $*$ & * & n.s. \\
\hline & Tsum & $* *$ & $*$ & n.s. \\
\hline \multirow[t]{14}{*}{ L.m } & Irrigation & * & n.s. & $*$ \\
\hline & K fertilizer $(50 \%)$ & n.s. & n.s. & $* *$ \\
\hline & K fertilizer $(60 \%)$ & n.s. & n.s. & n.s. \\
\hline & Solid N fertilizer & n.s. & * & n.s. \\
\hline & Manure type & n.s. & n.s. & n.s. \\
\hline & Manure amount & n.s. & n.s. & n.s. \\
\hline & $\mathrm{N}$ available from manure & n.s. & n.s. & n.s. \\
\hline & $\mathrm{N}$ during season from manure & n.s. & n.s. & n.s. \\
\hline & $\mathrm{P}$ from manure & n.s. & n.s. & * \\
\hline & $\mathrm{K}$ from manure & n.s. & n.s. & n.s. \\
\hline & $\mathrm{Mg}$ from manure & n.s. & n.s. & n.s. \\
\hline & $\mathrm{S}$ from manure & n.s. & n.s. & n.s. \\
\hline & $\mathrm{N}$ fertilizer based on sulfite & n.s. & n.s. & * \\
\hline & Urea & n.s. & $* * *$ & n.s. \\
\hline \multirow[t]{15}{*}{ L.s } & Clay fraction & n.s. & n.s. & $* *$ \\
\hline & Drought sensitivity & n.s. & n.s. & n.s. \\
\hline & GLS & * & * & n.s. \\
\hline & Groundwater level during winter & n.s. & n.s. & n.s. \\
\hline & B in soil & n.s. & n.s. & n.s. \\
\hline & Ca in soil & n.s. & n.s. & n.s. \\
\hline & Fe in soil & n.s. & n.s. & n.s. \\
\hline & $\mathrm{Mg}$ in soil & $*$ & n.s. & n.s. \\
\hline & Mn in soil & n.s. & n.s. & n.s. \\
\hline & $\mathrm{N}$ in soil & n.s. & n.s. & n.s. \\
\hline & $\mathrm{P}$ in soil & n.s. & n.s. & n.s. \\
\hline & $\mathrm{K}$ in soil & n.s. & $*$ & n.s. \\
\hline & Si in soil & n.s. & n.s. & n.s. \\
\hline & $\mathrm{Zn}$ in soil & n.s. & n.s. & n.s. \\
\hline & Nutrient content & n.s. & n.s. & n.s. \\
\hline \multirow[t]{3}{*}{ L.w } & Rainfall amount & n.s. & n.s. & n.s. \\
\hline & Rainfall duration & n.s. & $* * *$ & n.s. \\
\hline & Relative humidity & n.s. & n.s. & n.s. \\
\hline \multirow[t]{2}{*}{ R.m } & Granule & n.s. & n.s. & n.s. \\
\hline & Rotation crop & n.s. & n.s. & n.s. \\
\hline R.s & Nematodes & $* *$ & n.s. & n.s. \\
\hline
\end{tabular}

\section{Appendix E}

Table E.1

Counts per stem length cluster of the origin of the seed potatoes. Seed potato farmers are anonymized

\begin{tabular}{|c|c|c|c|c|c|c|c|c|c|c|c|c|}
\hline Cluster & Farm 1 & Farm 2 & Farm 3 & Farm 4 & Farm 5 & Farm 6 & Farm 7 & Farm 8 & Farm 9 & Farm 10 & Farm 11 & Farm 12 \\
\hline 1 & 1 & 1 & 0 & 0 & 0 & 0 & 0 & 0 & 0 & 0 & 0 & 2 \\
\hline 2 & 0 & 1 & 0 & 0 & 0 & 0 & 0 & 0 & 0 & 0 & 1 & 3 \\
\hline 3 & 0 & 0 & 0 & 0 & 3 & 0 & 7 & 0 & 1 & 0 & 0 & 8 \\
\hline 4 & 0 & 0 & 1 & 1 & 1 & 1 & 2 & 0 & 0 & 2 & 0 & 4 \\
\hline 5 & 0 & 0 & 0 & 0 & 1 & 0 & 0 & 2 & 0 & 0 & 1 & 5 \\
\hline 6 & 0 & 0 & 0 & 0 & 0 & 0 & 0 & 1 & 2 & 0 & 1 & 1 \\
\hline
\end{tabular}




\begin{tabular}{|c|c|c|c|c|c|c|c|c|c|c|c|c|}
\hline Cluster & Farm 13 & Farm 14 & Farm 15 & Farm 16 & Farm 17 & Farm 18 & Farm 19 & Farm 20 & Farm 21 & Farm 22 & Farm 23 & Farm 24 \\
\hline 1 & 0 & 0 & 0 & 0 & 1 & 1 & 1 & 0 & 0 & 0 & 0 & 1 \\
\hline 2 & 3 & 1 & 0 & 0 & 0 & 0 & 4 & 0 & 0 & 1 & 0 & 0 \\
\hline 3 & 1 & 0 & 0 & 0 & 2 & 2 & 7 & 0 & 0 & 1 & 0 & 1 \\
\hline 4 & 4 & 2 & 0 & 1 & 1 & 0 & 6 & 0 & 0 & 0 & 0 & 3 \\
\hline 5 & 5 & 1 & 0 & 1 & 3 & 0 & 10 & 1 & 0 & 0 & 0 & 2 \\
\hline 6 & 0 & 0 & 1 & 3 & 0 & 0 & 5 & 0 & 1 & 0 & 0 & 0 \\
\hline Cluster & \multicolumn{2}{|c|}{ Farm 25} & Farm 26 & \multicolumn{2}{|c|}{ Farm 27} & Farm 28 & \multicolumn{2}{|c|}{ Farm 29} & Farm 30 & \multicolumn{2}{|c|}{ Farm 31} & Farm 32 \\
\hline 1 & \multicolumn{2}{|c|}{0} & 2 & \multicolumn{2}{|c|}{2} & 1 & \multicolumn{2}{|c|}{0} & 0 & \multicolumn{2}{|c|}{3} & 0 \\
\hline 2 & \multicolumn{2}{|l|}{0} & 6 & \multicolumn{2}{|l|}{1} & 0 & \multicolumn{2}{|c|}{1} & 0 & \multicolumn{2}{|c|}{17} & 0 \\
\hline 3 & \multicolumn{2}{|l|}{0} & 8 & \multicolumn{2}{|l|}{0} & 0 & \multicolumn{2}{|c|}{10} & 0 & \multicolumn{2}{|c|}{2} & 0 \\
\hline 4 & \multicolumn{2}{|l|}{0} & 2 & \multicolumn{2}{|l|}{1} & 0 & \multicolumn{2}{|c|}{16} & 1 & \multicolumn{2}{|c|}{26} & 0 \\
\hline 5 & \multicolumn{2}{|l|}{0} & 3 & \multicolumn{2}{|l|}{0} & 0 & \multicolumn{2}{|c|}{11} & 0 & \multicolumn{2}{|c|}{14} & 0 \\
\hline 6 & \multicolumn{2}{|l|}{1} & 1 & \multicolumn{2}{|l|}{0} & 0 & \multicolumn{2}{|c|}{4} & 0 & \multicolumn{2}{|c|}{4} & 1 \\
\hline
\end{tabular}

\section{References}

Affholder, F., Poeydebat, C., Corbeels, M., Scopel, E., Tittonell, P., 2013. The yield gap of major food crops in family agriculture in the tropics: assessment and analysis through field surveys and modelling. Field Crop. Res. 143, 106-118. https://doi.org/ 10.1016/j.fcr.2012.10.021.

Alberda, T., 1962. Actual and Potential Production of Agricultural Crops. Technical Report 5.

Beza, E., Silva, J.V., Kooistra, L., Reidsma, P., 2017. Review of yield gap explaining factors and opportunities for alternative data collection approaches. Eur. J. Agric. 82, 206-222. https://doi.org/10.1016/j.eja.2016.06.016.

Bodlaender, K., 1960. De invloed van de temperatuur op de ontwikkeling van de aardappel. In: Jaarboek 1957-1969/Instituut voor Biologisch en Scheikundig Onderzoek van Landbouwgewassen 9/28-401/405. Instituut voor biologisch en scheikundig onderzoek van landbouwgewassen, pp. 69-83.

Boyd, N., Gordon, R., Martin, R., 2002. Relationship between leaf area index and ground cover in potato under different management conditions. Potato Res. 45, 117-129. https://doi.org/10.1007/BF02736107.

Caldiz, D.O., Fernandez, L.V., Struik, P.C., 2001. Physiological age index: a new, simple and reliable index to assess the physiological age of seed potato tubers based on haulm killing date and length of the incubation period. Field Crop. Res. 69, 69-79. https://doi.org/10.1016/S0378-4290(00)00134-9.

Cassman, K.G., Grassini, P., 2020. A global perspective on sustainable intensification research. Nat. Sustainabil. 3, 262-268.

Corwin, D., Lesch, S., 2005. Apparent soil electrical conductivity measurements in agriculture. Comput. Electron. Agric. 46, 11-43. https://doi.org/10.1016/j. compag.2004.10.005.

Curran, P.J., Obeidat, K., Losardo, D., 2010. Twelve frequently asked questions about growth curve modeling. J. Cogn. Dev. 11, 121-136. https://doi.org/10.1080/ 15248371003699969.

De Wit, C., 1959. Potential photosynthesis crop surfaces. Neth. J. Agric. Sci. 7, 141-149.

Deblonde, P., Ledent, J.-F., 2001. Effects of moderate drought conditions on green leaf number, stem height, leaf length and tuber yield of potato cultivars. Eur. J. Agron. 14, 31-41. https://doi.org/10.1016/S1161-0301(00)00081-2.

Delmotte, S., Tittonell, P., Mouret, J.-C., Hammond, R., Lopez-Ridaura, S., 2011. On farm assessment of rice yield variability and productivity gaps between organic and conventional cropping systems under Mediterranean climate. Eur. J. Agron. 35, 223-236. https://doi.org/10.1016/j.eja.2011.06.006.

Diogo, V., Reidsma, P., Schaap, B., Andree, B.P.J., Koomen, E., 2017. Assessing local and regional economic impacts of climatic extremes and feasibility of adaptation measures in Dutch arable farming systems. Agricult. Syst. 157, 216-229. https://doi. org/10.1016/j.agsy.2017.06.013.

Dormann, C.F., Elith, J., Bacher, S., Buchmann, C., Carl, G., Carré, G., Marquéz, J.R.G., Gruber, B., Lafourcade, B., Leit ao, P.J., et al., 2013. Collinearity: a review of methods to deal with it and a simulation study evaluating their performance. Ecography 36, 27-46.

Dunne, K., Willmott, C.J., 1996. Global distribution of plant-extractable water capacity of soil. Int. J. Climatol. 16, 841-859. https://doi.org/10.3334/ORNLDAAC/545.

Dyson, P., Watson, D., 1971. An analysis of the effects of nutrient supply on the growth of potato crops. Ann. Appl. Biol. 69, 47-63. https://doi.org/10.1111/j.17447348.1971.tb04657.x.

Edreira-Rattalino, J.I., Mourtzinis, S., Conley, S.P., Roth, A.C., Ciampitti, I.A., Licht, M. A., Kandel, H., Kyveryga, P.M., Lindsey, L.E., Mueller, D.S., et al., 2017. Assessing causes of yield gaps in agricultural areas with diversity in climate and soils. Agric. For. Meteorol. 247, 170-180. https://doi.org/10.1016/j.agrformet.2017.07.010.

Farran, I., Mingo-Castel, A., 2006. Potato minituber production using aeroponics: effect of plant density and harvesting intervals. Am. J. Potato Res. 83, 47-53. https://doi. org/10.1007/BF02869609.

Götze, P., Rücknagel, J., Jacobs, A., Märländer, B., Koch, H.-J., Holzweißig, B., Steinz, M., Christen, O., 2016. Sugar beet rotation effects on soil organic matter and calculated humus balance in central Germany. Eur. J. Agron. 76, 198-207. https:// doi.org/10.1016/j.eja.2015.12.004.
Grimm, K.J., Ram, N., Hamagami, F., 2011. Nonlinear growth curves in developmental research. Child Dev. 82, 1357-1371. https://doi.org/10.1111/j.1467. 8624.2011.01630.x.

van Heerwaarden, J., Baijukya, F., Kyei-Boahen, S., Adjei-Nsiah, S., Ebanyat, P., Kamai, N., Wolde-Meskel, E., Kanampiu, F., Vanlauwe, B., Giller, K., 2018. Soyabean response to rhizobium inoculation across sub-Saharan Africa: patterns of variation and the role of promiscuity. Agric. Ecosyst. Environ. 261, 211-218.

Hurvich, C.M., Tsai, C.-L., 1989. Regression and time series model selection in small samples. Biometrika 76, 297-307.

Ivins, J., Bremner, P., 1965. Growth, development and yield in the potato. Outlook Agric. 4, 211-217. https://doi.org/10.1177/003072706500400503.

Jain, A.K., 2010. Data clustering: 50 years beyond k-means. Pattern Recogn. Lett. 31, 651-666. https://doi.org/10.1016/j.patrec.2009.09.011.

Kachman, S.D., 2000. An introduction to generalized linear mixed models. Proceedings of a Symposium at the Organizational Meeting for a NCR Coordinating Committee on "Implementation Strategies for National Beef Cattle Evaluation". Citeseer, Athens, pp. 59-73.

Khurana, S., McLaren, J., 1982. The influence of leaf area, light interception and season on potato growth and yield. Potato Res. 25, 329-342. https://doi.org/10.1007/ BF02357290.

Kihara, J., Nziguheba, G., Zingore, S., Coulibaly, A., Esilaba, A., Kabambe, V., Njoroge, S., Palm, C., Huising, J., 2016. Understanding variability in crop response to fertilizer and amendments in sub-Saharan Africa. Agric. Ecosyst. Environ. 229, 1-12. https://doi.org/10.1016/j.agee.2016.05.012.

Kolbe, H., Stephan-Beckmann, S., 1997. Development, growth and chemical composition of the potato crop (Solanum tuberosum L.). I. Leaf and stem. Potato Res. 40, 111-129. https://doi.org/10.1007/BF02407567.

Laekemariam, F., Kibret, K., Shiferaw, H., 2018. Potassium (K)-to-magnesium (Mg) ratio, its spatial variability and implications to potential $\mathrm{Mg}$-induced $\mathrm{K}$ deficiency in Nitisols of Southern Ethiopia. Agric. Food Secur. 7, 13. https://doi.org/10.1186/ s40066-018-0165-5.

Lambert, 1990. De weergave van het grondwaterstandsverloop op bodemkaarten en grondsoorten. Databank Ondergrond Vlaanderen.

Laughlin, W.M., 1966. Effect of soil applications of potassium, magnesium sulfate and magnesium sulfate spray on potato yield, composition and nutrient uptake. Am. Potato J. 43, 403-411. https://doi.org/10.1007/BF02869565.

Lemaire, G., Gastal, F., Franzluebbers, A., Chabbi, A., 2015. Grassland-cropping rotations: an avenue for agricult. diversification to reconcile high production with environmental quality. Environ. Manag. 56, 1065-1077. https://doi.org/10.1007/ s00267-015-0561-6.

Lindstrom, M.J., Bates, D.M., 1990. Nonlinear mixed effects models for repeated measures data. Biometrics 673-687.

Lo, A., Chernoff, H., Zheng, T., Lo, S.-H., 2015. Why significant variables aren't automatically good predictors. Proc. Natl. Acad. Sci. U.S.A. 112, 13892-13897.

Lootsma, M., Scholte, K., 1997. Effect of soil moisture content on the suppression of rhizoctonia stem canker on potato by the nematode aphelenchus avenae and the springtail folsomia fimetaria. Plant Pathol. 46, 209-215. https://doi.org/10.1046/ j.1365-3059.1997.d01-229.x.

Maestrini, B., Basso, B., 2018. Drivers of within-field spatial and temporal variability of crop yield across the US Midwest. Sci. Rep. 8, 1-9.

Mandryk, M., Reidsma, P., van Ittersum, M.K., 2012. Scenarios of long-term farm structural change for application in climate change impact assessment. Landsc. Ecol. $27,509-527$.

Nuzzo, R., 2014. Statistical errors: P values, the 'gold standard' of statistical validity, are not as reliable as many scientists assume. Nature 506, 150-153.

Redulla, C., Davenport, J., Evans, R., Hattendorf, M., Alva, A., Boydston, R., 2002. Relating potato yield and quality to field scale variability in soil characteristics. Am. J. Potato Res. 79, 317-323. https://doi.org/10.1007/BF02870168.

Reidsma, P., Rietema, J., Yan, Y.L., Kroes, J., da Silva, J.N.V., 2015. Potential yield and yield gap at farm level are different from the field level: a case study on a large Dutch potato farm. 5th International Symposium for Farming Systems Design.

Riedell, W.E., Pikul, J.L., Jaradat, A.A., Schumacher, T.E., 2009. Crop rotation and nitrogen input effects on soil fertility, maize mineral nutrition, yield, and seed composition. Agron. J. 101, 870-879. https://doi.org/10.2134/agronj2008.0186x. 
Schaap, B.F., Reidsma, P., Verhagen, J., Wolf, J., Van Ittersum, M.K., 2013. Participatory design of farm level adaptation to climate risks in an arable region in the Netherlands. Eur. J. Agron. 48, 30-42. https://doi.org/10.1016/j.eja.2013.02.004. Schwarz, G., et al., 1978. Estimating the dimension of a model. Ann. Stat. 6, 461-464. Silva, J.V., Reidsma, P., Van Ittersum, M.K.a., 2017. Yield gaps in Dutch arable farming systems: analysis at crop and crop rotation level. Agric. Syst. 158, 78-92. https:// doi.org/10.1016/j.agsy.2017.06.005.

Silva, J.V., Tenreiro, T.R., Spätjens, L., Anten, N.P., van Ittersum, M.K., Reidsma, P., 2020. Can big data explain yield variability and water productivity in intensive cropping systems? Field Crops Res. 255, 107828.

Singer, J.D., 1998. Using SAS PROC MIXED to fit multilevel models, hierarchical models, and individual growth models. J. Educ. Behav. Stat. 23, 323-355. https://doi.org/ 10.3102/10769986023004323.

Steur, G., De Vries, F., Van Wallenburg, C., 1985. Bodemkaart van Nederland 1: 250 000: beknopte beschrijving van de kaarteenheden. Stiboka.

Struik, P.C., Wiersema, S.G., 1999. Seed Potato Technology. Wageningen Academic Pub.

Subedi, K., Ma, B., 2009. Assessment of some major yield-limiting factors on maize production in a humid temperate environment. Field Crop. Res. 110, 21-26. https:// doi.org/10.1016/j.fcr.2008.06.013.
Van Ittersum, M.K., Cassman, K.G., Grassini, P., Wolf, J., Tittonell, P., Hochman, Z., 2013. Yield gap analysis with local to global relevance - a review. Field Crop. Res. 143, 4-17. https://doi.org/10.1016/j.fcr.2012.09.009.

Van Ittersum, M.K., Leffelaar, P.A., Van Keulen, H., Kropff, M.J., Bastiaans, L., Goudriaan, J., 2003. On approaches and applications of the Wageningen crop models. Eur. J. Agron. 18, 201-234. https://doi.org/10.1016/S1161-0301(02) 00106-5.

Van Loon, C., 1981. The effect of water stress on potato growth, development, and yield. Am. Potato J. 58, 51-69. https://doi.org/10.1007/BF02855380.

Verbeke, G., Molenberghs, G., 2009. Linear Mixed Models for Longitudinal Data. Springer Science and Business Media.

Ward, M.D., Greenhill, B.D., Bakke, K.M., 2010. The perils of policy by p-value: predicting civil conflicts. J. Peace Res. 47, 363-375.

Wolfinger, R.D., 1999. Fitting nonlinear mixed models with the new nlmixed procedure. Proceedings of the 24th Annual SAS Users Group International Conference (SUGI 24) 278-284. 